\title{
The molecular mechanisms associated with the physiological responses to inflammation and oxidative stress in cardiovascular diseases
}

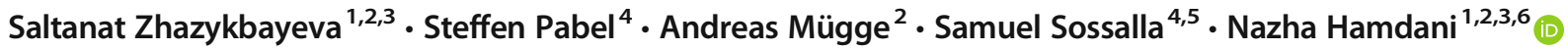

Received: 4 June 2020 / Accepted: 13 July 2020 / Published online: 21 July 2020

(C) The Author(s) 2020

\begin{abstract}
The complex physiological signal transduction networks that respond to the dual challenges of inflammatory and oxidative stress are major factors that promote the development of cardiovascular pathologies. These signaling networks contribute to the development of age-related diseases, suggesting crosstalk between the development of aging and cardiovascular disease. Inhibition and/or attenuation of these signaling networks also delays the onset of disease. Therefore, a concept of targeting the signaling networks that are involved in inflammation and oxidative stress may represent a novel treatment paradigm for many types of heart disease. In this review, we discuss the molecular mechanisms associated with the physiological responses to inflammation and oxidative stress especially in heart failure with preserved ejection fraction and emphasize the nature of the crosstalk of these signaling processes as well as possible therapeutic implications for cardiovascular medicine.
\end{abstract}

Keywords Molecular mechanisms $\cdot$ Cardiovascular diseases $\cdot$ Heart failure $\cdot$ Signaling pathways $\cdot$ Proteins modification

\section{Heart failure}

Heart failure (HF) is increasing in prevalence and now affects over $10 \%$ of those aged 70 years and over. HF is characterized by the activation of the sympathetic nervous and reninangiotensin-aldosterone systems, in a process of neuroendocrine activation that is associated with oxidative stress in the myocardium and vasculature. Oxidative stress occurs in the

Nazha Hamdani

nazha.hamdani@rub.de

1 Department of Molecular and Experimental Cardiology, Ruhr University Bochum, MABF 01/597, 44780 Bochum, Germany

2 Department of Cardiology, St. Josef-Hospital, Ruhr University Bochum, Bochum, Germany

3 Institute of Physiology, Ruhr University Bochum, Bochum, Germany

4 Department of Internal Medicine II, University Medical Center Regensburg, Regensburg, Germany

5 Clinic for Cardiology \& Pneumology, Georg-August University Goettingen, and DZHK (German Centre for Cardiovascular Research), partner site Goettingen, Germany

6 Department of Clinical Pharmacology, Ruhr University Bochum, Bochum, Germany myocardium (Franssen et al. 2016; Maack et al. 2003; Mollnau et al. 2005) and plasma and correlates with left ventricular (LV) dysfunction (Belch et al. 1991). Inflammation and oxidative stress are well known to promote HF phenotypes (Fig. 1). The processes of inflammation and oxidative stress are through physiological interactions to the activation of downstream networks that in turn promote various human pathologies, including aging, carcinogenesis, neurodegenerative disorders, and HF associated with various causes and phenotypes (Alegre-Cebollada et al. 2014; Choudhary and Dudley Jr. 2002; Grützner et al. 2009; Kötter et al. 2014; Matough et al. 2012). To understand the role of oxidation in the pathology of disease, in particular in those diseases that show abnormalities of diastolic function, it is crucial to elucidate the functional changes that occur during oxidative stress and how they result in HF (Fig. 1).

\section{Heart failure with preserved ejection fraction}

Heart failure with preserved ejection fraction (HFpEF) is characterized by high myocardial diastolic stiffness. Diastolic dysfunction is defined as the inability to fill the ventricle to an adequate preload volume (end-diastolic volume; EDV) at acceptably low pressures. Patients with abnormal diastolic 
function in particular HF with preserved ejection fraction (HFpEF) showed a complex remodeling of cardiomyocyte structure and function, in addition to a remodeling of the non-myocyte compartment (Borlaug and Kass 2006; Borlaug and Paulus 2011). Patients with abnormal diastolic function have a characteristic set of features including LV hypertrophy, concentric remodeling, increased extracellular matrix (ECM), abnormal calcium handling, abnormal relaxation and filling, and decreased diastolic distensibility. Diastolic function is often conceptualized as the totality of an active process of pressure decay (relaxation) during early diastole, which is related to myofilament dissociation and calcium reuptake, and to a "passive" stiffness dependent on viscoelastic properties, modulated by mechanical changes via the sarcomere, ECM, chamber, or pericardium (Linke and Hamdani 2014). Recent evidence suggests that oxidative stress may be the mechanistic link between obesity, diabetes mellitus, and related complications (Franssen et al. 2016; Herwig et al. 2020; Kolijn et al. 2020a; b). In obese patients, antioxidant defenses are lower than normal-weight counterparts and their levels inversely correlate with central adiposity; obesity is also characterized by enhanced levels of reactive oxygen or nitrogen species.

\section{Inflammation in heart failure}

Classic stimuli of ventricular remodeling such as wall stress, inflammatory cytokines, and neurohormones (e.g., catecholamines and angiotensin II) induce cellular changes that are at least partially mediated via oxidative or nitrosative stress (Arstall et al. 1999; Cheng et al. 1999; Communal et al. 1998; Nakamura et al. 1998; Xiao et al. 2002). Inflammation plays a central role in the development of HF, particularly in $\mathrm{HF}$ with preserved ejection fraction ( $\mathrm{HFpEF}$ ). The current rise in the prevalence of HF (Ponikowski et al. 2016b) can be explained by the increasing incidence of a range of comorbidities including renal failure, arterial hypertension, chronic obstructive pulmonary disease, diabetes mellitus, and metabolic syndrome (Fig. 1). These comorbidities are usually characterized by chronic inflammation and are of particular importance for patients with HFpEF (Ponikowski et al. 2016a). Inflammation is not only critical for the development and progression of $\mathrm{HFpEF}$, but the inflammatory response also plays an important role in adverse remodeling processes following myocardial infarction. The development of HF may also be directly immune-modulated, for example following autoimmune or infectious triggers such as viral infection. The inflammatory response is required to induce a regenerative response following acute myocardial injury and therefore also plays a positive role. However, sustained and chronic inflammation quickly becomes detrimental. The significance of inflammation in the development of HFpEF was firmly established in a swine model following induction of the three most common inflammation-associated comorbidities in HFpEF patients: arterial hypertension, diabetes mellitus, and hypercholesterolemia (Sorop et al. 2018). Together, these lead to diastolic dysfunction and HF, independent of coexisting coronary artery disease and hypertension. Increased inflammation is an important mechanism contributing to increased risk of $\mathrm{HF}$ in diabetic patients (Riehle and Abel 2016; Riehle and Bauersachs 2018). The underlying mechanisms of inflammatory-dependent HF in diabetic patients include increased expression levels of interleukins (IL) $1 \beta$ and 6 , intercellular adhesion molecule-1 (ICAM-1), and vascular cell adhesion molecule-1 (VCAM-1), together with decreased activity of collagen-degrading matrix metalloproteinase (Swinnen et al. 2009). Macrophages are also important mediators of inflammation and tissue remodeling in diabetes, and diverse inflammatory markers are associated with the development, diagnosis, and prognosis of patients with $\mathrm{HF}$ and $\mathrm{HFpEF}$ (Collier et al. 2011; Kalogeropoulos et al. 2010). The role of inflammation in the pathogenesis and progression of HF has important therapeutic and diagnostic implications (Briasoulis et al. 2016; Dick and Epelman 2016; Mehta and Pothineni 2016), but the question of whether inflammation is a direct cause of HF or only a marker of disease is still not completely resolved. Nevertheless, the association between the two has been shown in many studies, and pro-inflammatory biomarkers, specifically pro-inflammatory cytokines such as TNF- $\alpha$, IL-1, IL-6, and galectin-3, are known to be elevated in patients with a range of phenotypes and correlate with the prognosis and severity of disease (Dick and Epelman 2016; Franssen et al. 2016; Kolijn et al. 2020b). If inflammation is the cause of many forms of heart disease, then targeting the immune response may prove beneficial in patients with signs of inflammation. If this is not the case, it seems unlikely that a treatment targeting inflammation will prove effective in HF.

A central player of inflammation in many HF patients is obesity. Obesity is accompanied by increased visceral adipose tissue, which leads to the induction of several proinflammatory cytokines such as tumor necrosis factor- $\alpha$ (TNF $\alpha$ ), IL-6, monocyte chemoattractant protein 1, and other chemokine ligands, all of which lead to monocyte recruitment and macrophage activation. Increased peripheral inflammation, monocytosis, and monocyte differentiation to anti-inflammatory/profibrotic M2 macrophages have been associated with HFpEF in a population with a very high prevalence of metabolic comorbidities (Glezeva et al. 2015). Perivascular adipose tissue plays a major role in mediating vascular tone and endothelial inflammation through the mutual interaction of perivascular adipocytes, immune cells, vascular endothelium, and smooth muscle cells (Meijer et al. 2011). The effects can also be mediated by reduced expression of endothelial nitric oxide (NO) synthase (eNOS) and thus decreased NO synthesis, leading to reduced vasorelaxation. In addition, as 


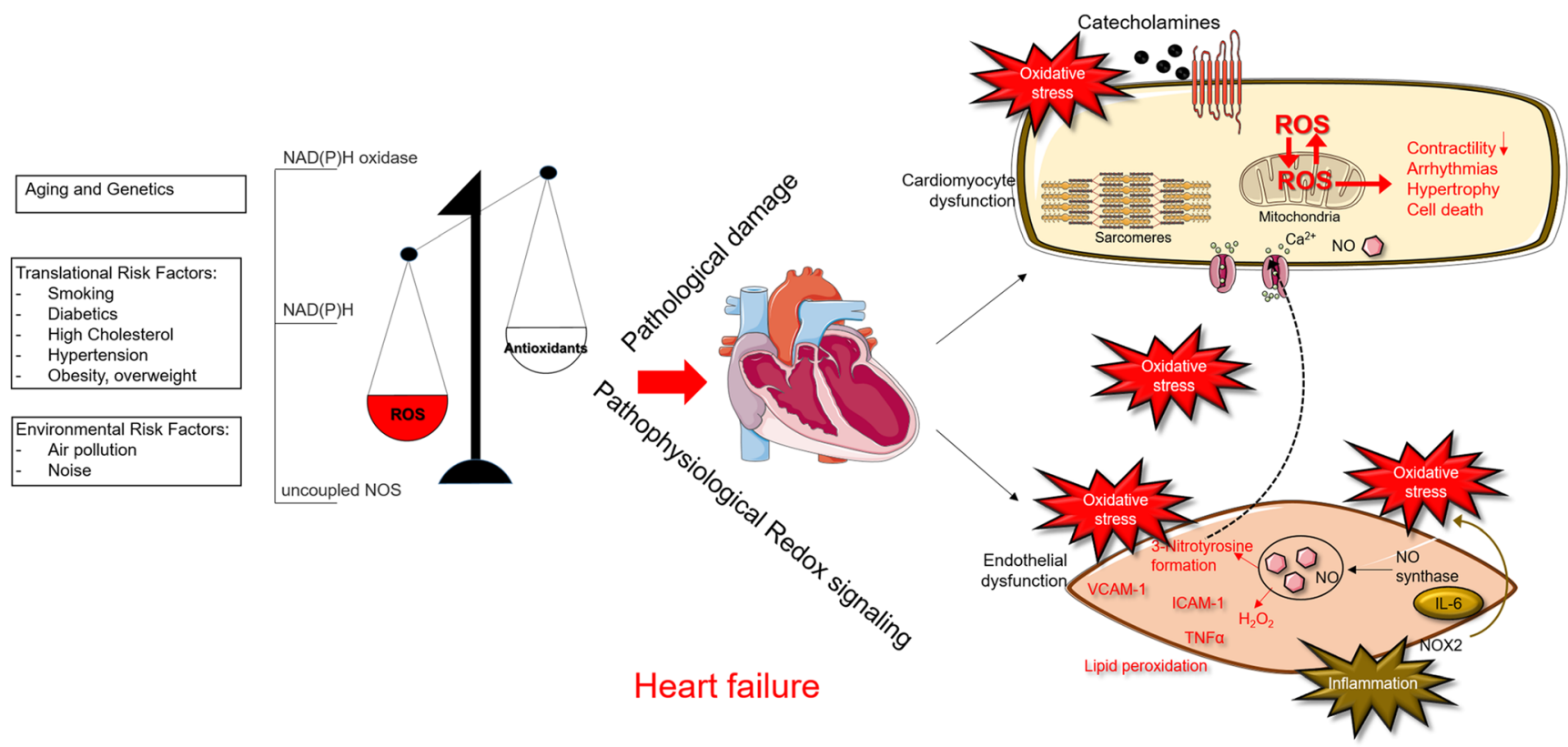

Fig. 1 Mechanisms, sources, and implications of oxidative stress in cardiovascular disease and heart failure. Aging, genetic predisposition, conventional risk factors, and environmental factors can induce oxidative stress, where NADPH, NOX, and uncoupled NOS are dominant sources of ROS. When the generation of ROS is greater than the antioxidative capacity, then cell damage and endothelial dysfunction arise due to increased ROS level. As a consequence, oxidation of mitochondrial $\mathrm{NADPH}, \mathrm{H} 2 \mathrm{O} 2$ is increased, which plays a causal role in contractile

obesity-associated inflammation also induces insulin resistance, an early step in the development of diabetes mellitus, comorbidities may interact. Obesity is defined as an expansion of adipose tissue as a result of excessive nutrient intake and insufficient energetic expenditure and may result in numerous different metabolic disorders including cardiovascular diseases, type 2 diabetes, and some forms of cancer. Obesity is associated with insulin resistance, which is a central component of type 2 diabetes, leading to altered glucose and lipid metabolism in adipose tissue, liver, and skeletal muscles. Insulin resistance is characterized by the failure of insulin to trigger the correct signaling mechanisms (Taniguchi et al. 2006). The chronic low-grade, systemic and local inflammation that develops during obesity links obesity to the development of insulin resistance (Gregor and Hotamisligil 2011), which then effects a variety of different organs involved in the control of metabolic homeostasis, including adipose tissue, liver, endocrine pancreas, hypothalamus, and possibly skeletal muscle. As adipocytes are a known source of proinflammatory cytokines, including TNF- $\alpha$, IL-1, and IL-6, obesity can be seen as a chronic inflammatory condition (de Almeida et al. 2020; Franssen et al. 2016; Schmidt-Lucke et al. 2015). These cytokines are known potent stimulators of the production of ROS and NOS by macrophages and monocytes and thereby increasing oxidative stress. Adipose tissue also has the capacity to secrete angiotensin II, which dysfunction, arrhythmia, and ultimately maladaptive cardiac remodeling through hypertrophy and cell death. Abbreviations: $\mathrm{H} 2 \mathrm{O} 2$, hydrogen peroxide; NADPH, nicotinamide adenine dinucleotide phosphate; NO, nitric oxide; NOS, nitric oxide synthase; NOX, nicotinamide adenine dinucleotide phosphate oxidase (NADPH oxidase); ROS, reactive oxygen species; IL, interleukin; ICAM, intercellular adhesion molecule; VCAM, vascular cell adhesion molecule; TNF- $\alpha$, tumor necrosis factor- $\alpha$

stimulates NADPH oxidase activity, which in turn represents the major source of ROS production in adipocytes (Morrow 2003). Furthermore, oxidative stress causes mitochondrial abnormalities, which then further escalate overproduction of ROS. Damage to mitochondria is significant because they provide a substantial proportion of the energy required for cellular processes and also play a central role in programed cell death (apoptosis) (Wang and Nakayama 2010).

The pathways that trigger the cellular phenotypes of hypertrophy and apoptosis appear to involve stress-responsive protein kinases such as mitogen-activated protein kinases (MAPK), c-Jun N-terminal kinases, and p38 MAPKs in the myocardium (Sugden and Clerk 1998b), many of which are activated by reactive oxygen species (ROS).

\section{Mechanical stress as a trigger of immune activation in heart failure}

The heart undergoes extensive structural and functional remodeling in response to injury, central to which is the hypertrophy of cardiac myocytes, which is characterized by the excessive deposition of extracellular matrix. Mechanical stress as a result of pressure and volume overload, together with shear stress, may induce cytokine expression and changes in cardiac extracellular matrix composition which in turn contribute to the pathogenesis of HF. In HF patients, the levels 
of a number of different cytokines such as TNF- $\alpha$, IL-1, 6, 18, cardiotrophin-1, and Fas ligand, as well as several chemokines, are elevated in the myocardium and plasma (Aukrust et al. 1999; Meldrum 1998; Testa et al. 1996). Cytokines are not only responsible for autocrine and paracrine signaling within the myocardium but also for endocrine signaling throughout the body, especially affecting striated muscle mass through the induction of muscle wasting and cachexia. Transforming growth factor signaling and alterations to the composition of the extracellular matrix induce acquisition of a myofibroblast phenotype (Koitabashi et al. 2011). Fibrosis is accelerated as a result of intercellular interactions and crosstalk between activated fibroblasts and cardiomyocytes (Burchfield et al. 2013).

Mechanical stress resulting in LV overload can also lead to myocardial inflammation, which manifests as leucocyte infiltration and the myocardial release of pro-inflammatory cytokines (Falkenham et al. 2015; Kain et al. 2016). Proinflammatory cytokines affect LV function, exert a negative inotropic effect (Meldrum 1998), induce abnormalities in cardiac metabolism and energetics, promote myocardial remodeling (Diwan et al. 2003; Mann 2002; Valgimigli et al. 2001), and depress myocardial contractility. The latter may be due to uncoupling of $\beta$-adrenergic signaling, increases in cardiac $\mathrm{NO}$, or alterations in intracellular calcium homeostasis (Finkel et al. 1992; Goldhaber et al. 1996; Gulick et al. 1989; Yokoyama et al. 1993). The result is cardiomyocyte hypertrophy (Yokoyama et al. 1997), necrosis, and apoptosis (Krown et al. 1996; Kubota et al. 1997), as well as activation of metalloproteinases, impaired expression of their inhibitors, and changes to the extracellular myocardial matrix, which together likely contribute to cardiac remodeling (Krown et al. 1996; Li et al. 2000; Pulkki 1997; Sivasubramanian et al. 2001). Resulting activation of the immune response also promotes the development of endothelial dysfunction, general body wasting, skeletal muscle apoptosis, and anorexia in HF (Sharma et al. 2000; Sivasubramanian et al. 2001; TorreAmione et al. 1996). Inflammatory mediators may also contribute more indirectly to the progression of HF through impairment of bone marrow function with secondary anemia, inappropriate endothelial cell activation, and impairment of peripheral muscle, with secondary induction of systemic inflammation and reflex abnormalities in HF (Mann 2002).

Hypoxia and ischemia are additional potent inducers of inflammatory cytokines within the myocardium and their effects are primarily mediated through the production of ROS, although secondary activation of the transcriptional factor nuclear factor- $\mathrm{KB}$ also plays an important role ( $\mathrm{Li}$ and Karin 1999; Singal et al. 1998). Finally, oxidized low-density lipoprotein cholesterol may increase cytokine expression in endothelial cells and monocytes, a mechanism that may be of particular importance in myocardial failure secondary to coronary artery disease (Janabi et al. 2000).

\section{Macrophages as key drivers of the innate immune response}

Macrophages are key mediators of the innate immune response, which is involved in the recognition, phagocytosis, and elimination of pathogens. They exist within the body as both circulating and tissue-resident cells and have the ability to transform their function and phenotype based on environmental signals (Murray and Wynn 2011). Macrophages are classified as either M1 or M2 types. M1 macrophages (Murray et al. 2014) are usually associated with a proinflammatory response and are referred to as classically activated macrophages, with induction mediated by IFN $\gamma$, lipopolysaccharide, and TNF- $\alpha$. When stimulated, M1 macrophages secrete high levels of pro-inflammatory cytokine interleukins (Martinez et al. 2008). By contrast, M2 macrophages exhibit an anti-inflammatory, pro-regenerative phenotype due to their capacity to secrete high levels of anti-inflammatory cytokines, including IL-10 and certain growth factors (Martinez et al. 2008). After angiotensin II infusion or transverse aortic constriction, macrophages are important mediators of hypertension, cardiac remodeling, and fibrosis, and depletion of macrophages results in reduced cardiac fibrosis and decreased LV hypertrophy (Falkenham et al. 2015; Kain et al. 2016). The pathological processes in many disease models are fueled by macrophage-derived cytokines (Heymans et al. 2013). Depletion of monocytes and macrophages in chronic HF models of mechanical stress prevents LV remodeling, fibrosis and preserves cardiac function (Dewald et al. 2005; Frantz et al. 2013; Kain et al. 2016; van Amerongen et al. 2007). Mice with macrophage-specific deletion of IL-10 show improved diastolic function. IL10 may promote fibrosis by activating fibroblasts, increasing collagen deposition, and impairing myocardial relaxation (Hulsmans et al. 2018).

Inflammation promotes cardiac fibrosis in HFpEF mouse models (Glezeva and Baugh 2014; Tromp et al. 2018), and increased numbers of macrophages have been observed in HFpEF patients and appear to contribute to pathophysiology (Hulsmans et al. 2018). Fibrosis is thus heavily implicated in the development of LV diastolic dysfunction and, in addition to reduced ventricular compliance and comorbidities, may be one of the major pathophysiological mechanisms underlying HFpEF (Bode et al. 2019; Hamdani et al. 2013a; 2014; Trippel et al. 2018). Increased inflammation, elevated levels of endothelial adhesion molecules, and increased production and tissue release of inflammatory cytokines and chemokines are the earliest events found in cardiac stress states in HFpEF, including pressure and/or volume overload (Paulus and Tschöpe 2013). These states promote the infiltration of activated inflammatory cells, particularly monocytes, into cardiac tissue, and increased monocyte infiltration is also seen in hypertension and HFpEF. Once in place in tissue, monocytes 
differentiate into macrophages and promote cardiac inflammation, tissue injury, and myocardial fibrosis (Paulus and Tschöpe 2013). In coronary artery disease, resident macrophages distinct from monocyte-derived macrophages contribute to pathology (Honold and Nahrendorf 2018). Two mouse models of LV diastolic dysfunction, induced by either hypertension or advanced age, showed increased macrophage density in the LV compared with control mice, a finding associated with increased inflammatory monocytes (Hulsmans et al. 2018). In line with these findings, LV myocardial biopsies from patients with hypertension and HFpEF had higher macrophage densities compared with those from age-matched healthy controls (Hulsmans et al. 2018). The myocardial infiltration of inflammatory cells in HFpEF patients and in ZSF1HFpEF rats is favored by adhesion molecules, an effect evidenced by the presence of NOX2-producing macrophages and by the high expression of CD68 (Franssen et al. 2016). In contrast to viral myocarditis, the myocardial presence of macrophages in HFpEF is not accompanied by evidence of cardiomyocyte cell death (van Heerebeek et al. 2006; 2008), perhaps due to the fact that macrophages activated due to obesity show a different pro-inflammatory phenotype (Kratz et al. 2014).

Importantly and as already mentioned, classically conceived macrophage activation proceeds via either an M1 phenotype, with potent pro-inflammatory properties, or via an M2 phenotype, with anti-inflammatory properties. However, when activated by obesity, a distinct macrophage phenotype is induced that is characterized by low levels of proinflammatory cytokines. Another study has also reported that the development of HFpEF is associated with monocytosis and monocyte differentiation into M2-like macrophages (Glezeva et al. 2015; Hulsmans et al. 2018). Furthermore, patients with HFpEF show increased levels of blood leukocytes and monocytes (Hulsmans et al. 2018). Taken together, these findings imply that the expansion of and phenotypic changes in cardiac macrophages may represent viable therapeutic targets when seeking to limit the cardiac inflammation that leads to diastolic dysfunction.

\section{What is oxidative stress?}

Oxidative stress is defined based on a description of the origin of the type of ROS and other free radicals. Oxidative stress is an important contributor to tissue damage, and the cellular damage caused by oxidative stress elicits complex antioxidant defense mechanisms that have co-evolved to protect body tissues. As free radicals are constantly produced during normal metabolic processes in cells, antioxidants are also produced to ensure neutralization of free radicals. Under normal conditions, the body is usually able to maintain an equilibrium between free radicals and antioxidants.
Severe oxidative stress represents a threat to cell function and therefore results in the activation of repair mechanisms. On the other hand, disturbance in ROS levels appears to be involved in growth factor and other receptor-mediated cell signaling processes. ROS negatively affects the disposition of myocardial calcium, may induce arrhythmia, and can contribute to cardiac remodeling by inducing hypertrophic signaling, apoptosis, and necrosis (Burgoyne et al. 2012a; Wagner et al. 2013). ROS and nitric oxide (NO) produced from these sources are oxygen-/nitrogen-based chemical species with a high reactivity and include free radicals such as superoxide ion $(\mathrm{O} 2 \cdot-)$, hydroxyl radical $(\bullet \mathrm{OH})$, and peroxy radicals ( $\mathrm{ROO} \bullet$, as well as non-radicals that are nevertheless able to generate free radicals, such as hydrogen peroxide (H2O2), nitroxyl, and NO (Breitkreuz and Hamdani 2015). A diminished capacity of nitric oxide synthase (NOS) to generate NO (Pitocco et al. 2010; Sena et al. 2013) is accompanied by increased oxidative stress during diabetic vascular dysfunction (Giugliano et al. 1996). The likely mechanism is via a superoxide ion that reacts with $\mathrm{NO}$, resulting in the formation of peroxynitrite. Peroxynitrite then oxidizes the endothelial NOS (eNOS) cofactor tetrahydrobiopterin (BH4) to dihydrobiopterin (BH2), leading to eNOS uncoupling and thus producing superoxide ion rather than NO. This mechanism leads to a decrease in eNOS expression and activity in endothelial cells (Cosentino and Lüscher 1997; Srinivasan et al. 2004).

ROS are generated as metabolic by-products by biological systems (enzymatic reactions) in various cell compartments, including the cytoplasm, cell membrane, endoplasmic reticulum (ER), mitochondria, and peroxisome, all as through basal metabolic activity. In cardiomyocytes, ROS typically originate from several intracellular sources, including mitochondria, NOS, and enzymes such as xanthine oxidase, NADPH oxidase (NOX), and cytochrome p450 (Dostalek et al. 2008; Gori and Münzel 2011; Ji 2007; Srinivasan et al. 2004; Sumimoto et al. 2005; Zangar et al. 2004) (Fig. 2). Importantly, mitochondria amplify ROS derived from NOXs and may thereby function as "redox hubs" in cardiac physiology and disease (Navarro-Yepes et al. 2014; Sato et al. 2013). Additionally, many other enzymes, such as cyclooxygenases and lipoxygenases, may contribute to intracellular ROS production (Holmström and Finkel 2014). Along with resident cardiac cells, infiltrated leukocytes account for a large proportion of ROS and reactive nitrogen species (RNS) in myocardial tissues, via the production of superoxide ion and release of pro-oxidant enzyme systems like the leukocyte-derived enzyme myeloperoxidase (MPO). ROS are produced by mitochondria (Li et al. 2013; 2017; Reichart et al. 2019), which mainly takes place at the electron transport chain located on the inner mitochondrial membrane during the process of oxidative phosphorylation. Leakage of electrons at complex I and complex III from electron transport chains leads to a partial 
reduction of oxygen to form superoxide. Consequently, superoxide is dismutated to hydrogen peroxide by two dismutases including superoxide dismutase 2 in mitochondrial matrix and superoxide dismutase 1 in mitochondrial intermembrane space and both superoxide and hydrogen peroxide generated are considered mitochondrial ROS (Li et al. 2013).

Different signals lead to the stimulation of mitochondrial ROS such as lysophosphatidylcholine and Toll-like receptor 4 and Toll-like receptor 2 bacterial ligands lipopolysaccharide and lipopeptides; these signals are involved in regulating inflammatory response ( $\mathrm{Li}$ et al. 2016; West et al. 2011). Among others, mitochondrial ROS adversely affects ECcoupling (Bertero and Maack 2018) and can induce cell death via activation of apoptosis and/or autophagy pathways (Finkel 2012). As previously discussed, under normal physiological conditions, the tissue oxidative balance is maintained by mobilizing an antioxidant defense system that eliminates harmful reactive oxygen/nitrogen species (ROS/NOS). Several distinct types of ROS have been identified, each of which is targeted by specific antioxidant enzymes. The one-electron reduction of $\mathrm{O} 2$ leads to the formation of superoxide anion, an unstable free radical that reacts with itself and other oxygen-containing species. Redox biology refers to low levels of ROS that activate signaling pathways to initiate biological processes, while oxidative stress denotes high levels of ROS that cause damage to DNA, protein, or lipids leading to different diseases.

Proteins, lipids, and DNA are the primary cellular structures affected by ROS and RNS (Wu et al. 2013). A large body of evidence shows that oxidative stress is implicated in the onset and progression of diseases such as cancer, diabetes, metabolic disorders, and atherosclerosis, in addition to cardiovascular diseases (Taniyama and Griendling 2003). Depending on the source of ROS, cell type, and tissue environment, ROS signaling may simply participate in normal physiological processes or contribute to a maladaptive response that leads to metabolic dysfunction and inflammatory signaling.

\section{Oxidative stress and inflammation in cardiovascular diseases}

One potential trigger of HF-associated changes in muscle protein function, some of which are characterized by an increase in LV diastolic stiffness, is the oxidative stress that results a

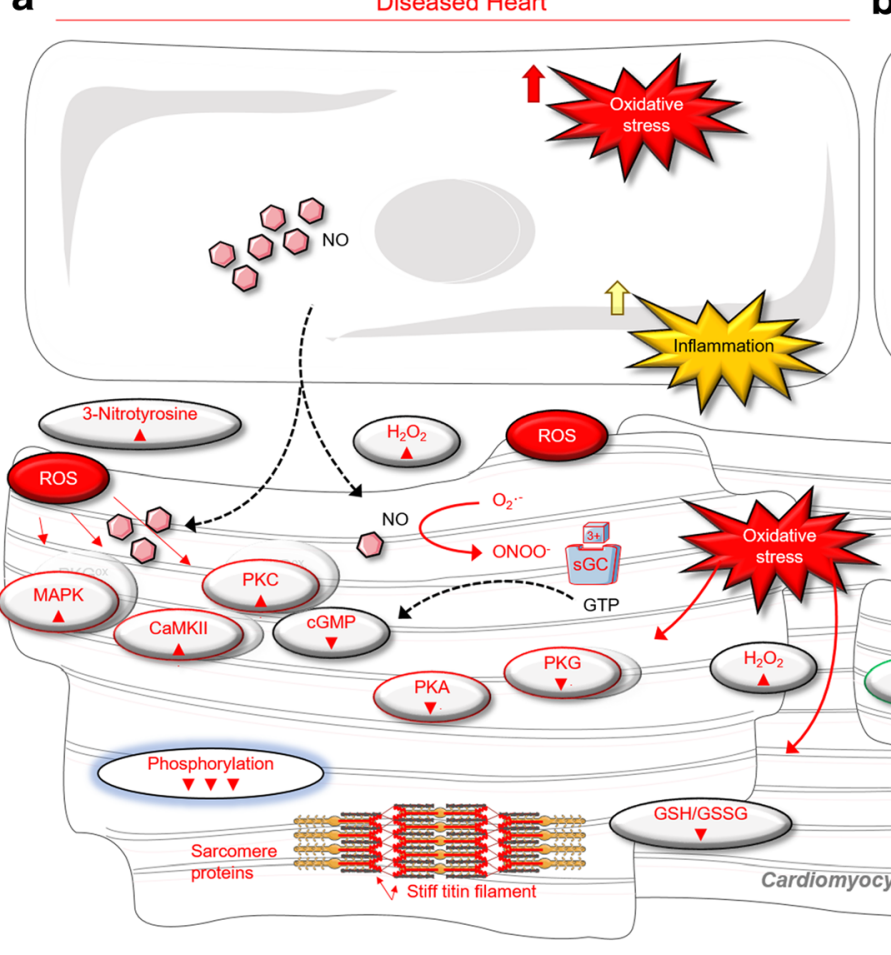

b Healthy Heart

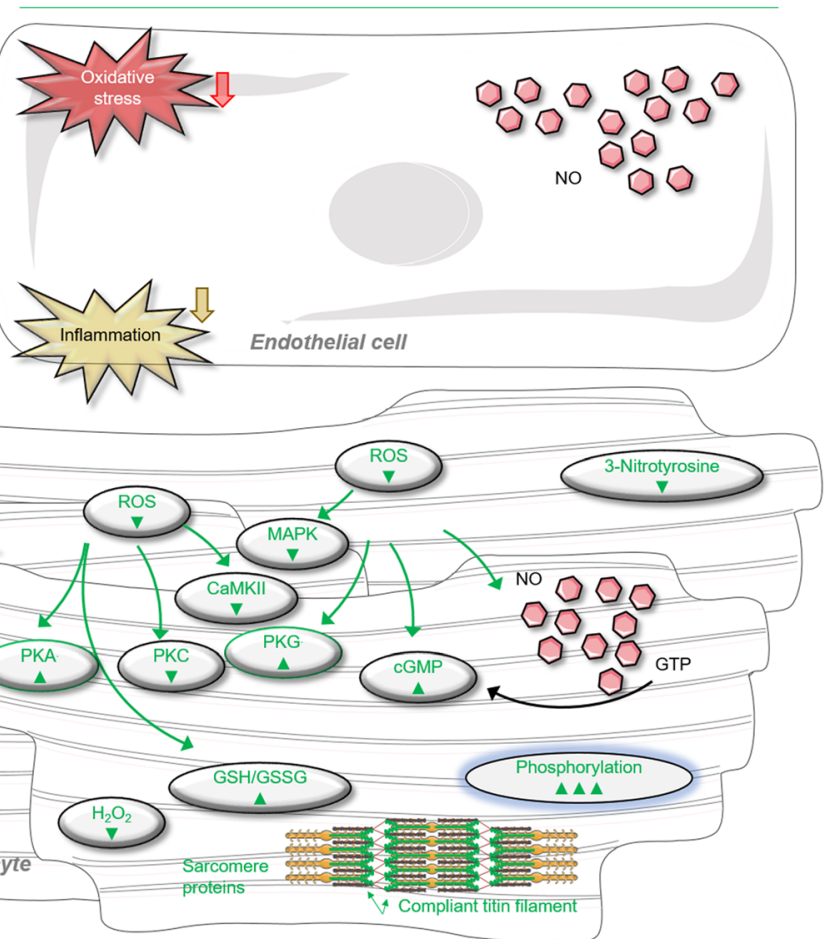

Fig. 2 Scheme for the signaling pathways of cardiomyocyte in diseased heart under oxidative (right) and healthy (left) conditions. A Represents a heart under oxidative condition with impaired endothelial function via increased inflammatory cytokines and oxidative stress. B Represents a healthy condition showing a normal endothelial function via normal/low inflammatory cytokines and oxidative stress (green arrow pointing upwards means increase and green arrow pointing down means decrease).
Abbreviations: cGMP, cyclic guanosine monophosphate; GTP, guanosine triphosphate; $\mathrm{PKG}$, protein kinase $\mathrm{G} ; \mathrm{H}_{2} \mathrm{O}_{2}$, hydrogen peroxide; NO, nitric oxide; ONOO-, peroxynitrite; PKG, protein kinase G; PKA, protein kinase $\mathrm{A}$; $\mathrm{PKC}$, protein kinase $\mathrm{C}$; CaMKII, calcium calmodulindependent kinase II; MAPK, mitogen-activated protein kinase; ROS, reactive oxygen species; sGC, soluble guanylyl cyclase; GSH, reduced glutathione; GSSG, oxidized glutathione 
from imbalances in cellular antioxidant systems and free radical production. High levels of ROS production that overwhelm cellular antioxidant defense systems are generally deleterious to contractile performance and result in adverse cardiac and skeletal remodeling. In cardiomyocytes, several intracellular sources of ROS/ RNS are typically found under physiological conditions, and tissue oxidative balance is maintained by utilizing an antioxidant defense system that removes harmful ROS/NOS. The mechanism by which myocardial oxidative stress might impair cardiac function is probably oxidative damage to cellular proteins and membranes, thereby inducing cellular dysfunction or death through apoptosis and/or necrosis. However, recent studies in other organ systems indicate that ROS can exert much subtler effects, depending upon the level, the site of production, and the overall redox status of the cell (Borkowski et al. 2011; Campbell et al. 1996; Xu et al. 1998).

ROS may also activate signaling pathways that contribute to ischemic preconditioning, cardioprotection, and myocardial damage, and high levels of ROS induce structural modifications of the sarcomere that impact pump function and the general pathogenesis of HF. Many of the characteristic cellular responses found in HF can be activated by oxidative stress, including cellular hypertrophy, changes in gene expression, and cell death (Kwon et al. 2003; Siwik et al. 1999). For instance, cell growth, a hypertrophic phenotype, and apoptosis in neonatal rat cardiac myocytes in vitro can all be induced by inhibition of the antioxidant enzyme, copper-zinc superoxide dismutase (Siwik et al. 1999). Hydrogen peroxide regulates the phenotype of cardiac myocytes via concentration-dependent activation of different kinase pathways (Kwon et al. 2003), in addition to altering the turnover and properties of the extracellular matrix (Siwik et al. 2001). ROS can also exert subtler effects, depending on the level of ROS and the redox status of the cell. Regardless of the crucial role of antioxidant systems, dysregulation of oxidant signaling may cause or accelerate a host of pathological conditions. Nevertheless, the body is armed with protective measures against ROS via enzymatic superoxide dismutase, catalase, peroxiredoxin, and glutathione peroxidase, as well as non-enzymatic compounds such as vitamin E, beta-carotene, ascorbate, glutathione, and nicotinamide (Balaban et al. 2005).

Structural modifications in cardiomyocytes are caused by alterations either of protein expression, phosphorylation, or function and have been attributed to the activation of signaling pathways. In turn, these lead to changes in the magnitude of the calcium transients and an inadequate calciuminduced contractile response, or induce contractile protein modifications independent of alterations to intracellular calcium homeostasis (Adachi et al. 2004; Lancel et al. 2009; $\mathrm{Xu}$ et al. 1998).

\section{Oxidative stress and redox regulation in cardiomyocytes}

Cardiac contraction is dynamically regulated on a beat-to-beat basis in order to accommodate changes in hemodynamic load and to respond to neurohumeral stresses. Control is predominantly signal-regulated via various post-translational modifications, and signaling by ROS has recently emerged as a major physiological control mechanism (Breitkreuz and Hamdani 2015). Furthermore, redox protein modifications are known to induce changes in protein structure, stability, interactivity, and activity (Fig. 2) (Disatnik et al. 1998; Gao et al. 1996; Posterino and Lamb 1996).

Myocytes isolated from the failing heart show abnormal intracellular calcium transients, along with alterations in the expression and/or activity of calcium handling proteins (Arai et al. 1993), an effect that is partly due to oxidative stress (Fig. 2). Functional changes in calcium handling are linked to posttranslational modification of calcium signaling proteins, as well as oxidative and nitrosative regulation of the calciumsensitive proteome in excitation-contraction coupling (Canton et al. 2014; Haycock et al. 1996; Posterino and Lamb 1996; Ullrich et al. 2009). ROS alter calcium transients and excitation-contraction coupling in isolated myocytes by increasing the activity of the sodium-calcium exchanger, which lead to calcium overload in human and animal models (Arai et al. 1993; Goldhaber and Qayyum 2000; Litwin and Bridge 1997). A direct effect of ROS and RNS on voltagedependent calcium channels and calcium release channels has been noted in isolated cardiomyocytes and attributed to the activation of kinase cascades and cell death pathways, including apoptosis and necroptosis (Adachi et al. 2004; Borkowski et al. 2011; Campbell et al. 1996). ROS generation might also contribute to the activation of maladaptive signaling cascades, e.g., those leading to impaired calcium handling.

Calcium channels associated with excitation-contraction coupling regulate myoplasmic calcium levels and are organized around a system of deep membrane invaginations known as t-tubules. Depolarization of the sarcolemma leads to calcium influx into the sarcoplasm and triggers the release of calcium from the sarcoplasmic reticulum via the ryanodine receptor (calcium-induced calcium release). Changes in intracellular calcium cycling are either causal or adaptive (Bellinger et al. 2009; Durham et al. 2008; Zalk et al. 2007). Abnormalities in excitation-contraction coupling components trigger and/or aggravate contractile dysfunction and have been partially attributed to redox modifications that act as key signaling components of excitation-contraction coupling (Canton et al. 2014; Disatnik et al. 1998; Gao et al. 1996; Posterino and Lamb 1996). The redox modification of protein kinase activity and direct effects on channels and ion transporters are among the well-known effects of ROS on excitation-contraction coupling (Wagner et al. 2013). 


\section{Modification of redox-related signaling pathways}

Redox-modulated protein signaling activities that are important for cardiomyocyte function are often mediated via protein kinase A (PKA) (Brennan et al. 2006), protein kinase G (PKG) (Burgoyne et al. 2007), or calcium calmodulindependent kinase II (CaMKII), in addition to important contributions from the small $\mathrm{G}$ protein Ras (stress signaling) (Kuster et al. 2006), class II histone deacetylases (HDACs) (Ago et al. 2008), and the metabolic enzymes glyceraldehyde3-phosphate dehydrogenase and thioredoxin (Eaton et al. 2002b; Tisdale 2002). The balance between oxidized and reduced forms of such signaling proteins is influenced by both local ROS generation and by reductants such as glutathione, which function to reduce oxidized proteins.

\section{CAMP-dependent protein kinase $A$ and CGMP-dependent protein kinase $G$}

Protein kinase $\mathrm{A} \beta$-Adrenergic activation via protein kinase $\mathrm{A}$ (PKA)-mediated phosphorylation targets several proteins involved in calcium handling, including the L-type calcium channel (LTCC), sarco-/endoplasmic reticulum Ca2+ATPase (SERCA), ryanodine receptors (RyR), and myofilament proteins such as cardiac troponin I (cTnI), myosinbinding protein $\mathrm{C}$ (cMyBPC), and the giant protein titin (Hamdani et al. 2013a; b; 2014; 2008; 2009). Catecholamine stimulation of the $\beta$-adrenergic receptors in the myocardium plays an important role in adjusting myocardial performance to meet increased demands of the heart, as occurs upon increased stress (e.g., exercise). Phosphorylation of calcium handling and myofilament proteins regulates contractile function of the heart via its positive lusitropic effect and its contribution to an acceleration of the rate of cardiac relaxation (Fig. 2) (Gaponenko et al. 1999; Hamdani et al. 2008; Kentish et al. 2001; Lehnart et al. 2004). Alterations in PKA-mediated phosphorylation in HF have been reported following catecholamine overstimulation of the $\beta$-adrenergic receptors. In HF, the RyR2 receptors are hyperphosphorylated (Lehnart et al. 2004) and many myofilament proteins (such as cTnI, cMyBPC, and titin) are hypophosphorylated (Hamdani et al. 2008; Solaro 2008; Solaro and de Tombe 2008) (with an exception of some phospho-sites on titin that become hyperphosphorylated when they are targeted by PKC and CaMKII, two kinases upregulated in HF) (Hamdani et al. 2013b). These changes all seem to be detrimental to cardiac performance. In addition, leakage of calcium from the SR, which increases cytosolic calcium levels during diastole and enhances myofilament calcium sensitivity, results in an increase in passive stiffness that limits relaxation of the heart muscle (Hamdani et al. 2013a; Herwig et al. 2020; Kolijn et al. 2020b; Pabel et al. 2018; van Heerebeek et al. 2008).
PKA can also be activated by redox changes acting through the formation of an inter-disulfide bond between its catalytic subunits (Brennan et al. 2006). A similar mechanism of redox activation has also been reported for PKG (Burgoyne et al. 2007). Oxidative modifications of PKA alter its activity and lead to functional and physiological consequences such as impaired insulin-stimulated lipolysis (de Piña et al. 2008). In addition, oxidation of PKA mediated by oxidants derived from NADPH oxidase 4 stimulates angiogenesis via vascular endothelial growth factor (Burgoyne et al. 2015). Modulation of cardiomyocyte stiffness via altered PKA activity has been noted in HF patients and animal models with several different types of heart disease (Hamdani et al. 2013a; Kolijn et al. 2020b). Overall, the changes noted in diseased hearts were associated with a chronic titin phosphorylation deficit related to the modulation of PKA activity. Titin can also be phosphorylated by a range of additional kinases such as protein kinase $\mathrm{G}(\mathrm{PKG})$, protein kinase $\mathrm{C}$ (PKC), protein kinase D (PKD), extracellular signal-regulated kinases (ERK), and calcium calmodulin-dependent protein kinase II (CaMKII) (Fig. 2).

Titin isoform switching The titin protein consists of two main isoforms, N2BA (long and compliant) and N2B (short and stiff), and acts as a molecular spring with a crucial role in LV diastolic stiffness (Hamdani et al. 2017; Hamdani et al. 2013c; Linke and Hamdani 2014). Titin is responsible for the passive elasticity of muscle through isoform switching or post-translational modifications such as phosphorylation and oxidation. Different isoforms result from differential splicing of a single titin gene and differ in their expression level depending on the heart phenotype and disease stage. Expression of either the long and compliant N2BA or the short and stiff N2B isoform significantly influences titin-based stiffness, which then modulates diastolic function (Hamdani et al. 2017; Hamdani et al. 2013c; Linke and Hamdani 2014). By contrast, phosphorylation has rapid effects compared with isoform switching and contributes to either increased or reduced cardiomyocyte stiffness, depending on the type of kinase (Hamdani et al. 2017; Hamdani et al. 2013c; Linke and Hamdani 2014).

Protein kinase G PKG regulates the function of target proteins by phosphorylating serine or threonine residues. It is a wellknown modulator of diastolic function and can be modified directly and indirectly via ROS. Cyclic guanosine monophosphate (cGMP)-directed PKG signaling is initiated by soluble guanylate cyclase (sGC) or particulate GC (pGC), both lyase enzymes that convert guanosine triphosphate (GTP) to cyclic guanosine monophosphate. sGC is activated by NO, which then generates cGMP from GTP (Fig. 2) (Klaiber et al. 2011; Kuhn 2004; Moltzau et al. 2014a; b). pGC is activated by natriuretic peptides (NPs), including atrial $\mathrm{NP}$ and B-type NP, which bind to shared, membrane-bound 
GC-A or GC-C receptors. The activation of $\mathrm{pGC}$ can also occur through C-type NP binding to GC-B or GC-C receptors (Klaiber et al. 2011; Kuhn 2004; Moltzau et al. 2014a; b). sGC and pGC generate spatially and functionally distinct cellular pools of cGMP (Klaiber et al. 2011; Kuhn 2004) that are tightly controlled by phosphodiesterases (PDEs) (Bishu et al. 2011; Hamdani et al. 2014; Lee et al. 2015). However, the relative importance of the respective cGMP pools for HF may differ depending on comorbidities and sex-related differences, although the details of this process are still unknown. ROS can directly modify PKG via oxidation, as reduced PKGI $\alpha$ activity and increased PKGI $\alpha$ oxidation were found in human HFpEF myocardium and ZDF rats and correlated significantly with increased myocardial oxidative stress, specifically in the cytosol and mitochondria (Kolijn et al. 2020b). Studies suggested that PKGI $\alpha$ oxidation would likely increase the activity of the kinase (Prysyazhna et al. 2012), while other studies reported similar PKGI $\alpha$ activity in both WT and PKGI $\alpha$ Redox dead' cysteine-42S (C42S) PKG1 $\alpha$ knockin mice (TAC myocardium), mice harboring a knockin redox-dead mutation PKG1 $\alpha \mathrm{C} 42 \mathrm{~S}$, perhaps due to a higher cGMP level that might blunt changes in oxidative activity (Burgoyne et al. 2007; 2012b). Furthermore, C42 oxidation reportedly reduces the capacity for activation PKGI $\alpha$ when countering hormone, hemodynamic (Nakamura et al. 2015), and cardiotoxic stress (Prysyazhna et al. 2016). Others have reported that the interprotomer disulfide bond is not required for oxidationinduced activation, as shown by a truncated PKGI $\alpha$ construct (Prysyazhna et al. 2012). Unsurprisingly, PKGI $\alpha$ oxidation is increased in human ischemic HF, in mouse hearts exposed to sustained pressure overload, and in canine-dilated cardiomyopathy (Nakamura et al. 2015).

Modifications of cardiomyocyte function in HF are associated with alterations in cGMP-PKG signaling due to oxidative stress (indirect ROS effect on cardiomyocyte modifications) (Fig. 2). Normally, NO activates sGC in a process involving the binding of NO to the heme moiety of sGC, augmenting the action of cGMP. However, the superoxide anion is a potent inactivator of the signaling molecule $\mathrm{NO}$; the resulting reduction in NO bioavailability contributes to vascular endothelial dysfunction and the loss of other physiological effects of NO (Fig. 2). The reaction between NO and superoxide generates peroxynitrite, which is itself a potent RNS. Hence, ROS can modulate the activity of various intracellular signaling pathways and molecules, potentially inducing acute and chronic modifications (Finkel 1999; Hamdani et al. 2013a; b; 2014). Signal transduction by ROS in non-phagocytic cells (Finkel 1999) can be mediated via proteins involved in myocardial excitation-contraction coupling (including ion channels, sarcoplasmic reticulum calcium-release channels, and myofilament proteins), as these proteins are prone to redox-sensitive alterations in an activity that ultimately modify cardiomyocyte function (Byrne et al. 2003; Linke and Hamdani 2014). In addition, stimulation of $\mathrm{NO}$ and/or activation of sGC promotes cGMP and PKG activation (Kolijn et al. 2020b; Linke and Hamdani 2014). Oxidative stress affects these pathways by lowering NO bioavailability, blocking sGC activity, increasing cGMP-specific phosphodiesterase-5A, and downregulating cGMP-PKG signaling (Franssen et al. 2016; Herwig et al. 2020; Kolijn et al. 2020b). Reduced PKG activity due to oxidative stress will then lead, among other outcomes, to hypophosphorylation of the giant titin, raising cardiomyocyte passive tension (Fig. 2). Accordingly, hearts from HFpEF patients and a small animal model of HFpEF (which exhibit reduced cGMP concentrations, reduced PKG activity, hypophosphorylated titin, and high cardiomyocyte passive stiffness) also show increased nitrotyrosine levels, indicative of nitrosative/oxidative stress (Borbély et al. 2009; Franssen et al. 2016; Hamdani et al. 2013a; b; 2014; van Heerebeek et al. 2012). These findings point to oxidative/nitrosative stress as an indirect modifier of titin phosphorylation and stiffness, which could eventually lead to diastolic dysfunction (Fig. 3). If so, many patients with HFpEF might develop diastolic dysfunction, not least because they are typically older and have various comorbidities including renal insufficiency, obesity, diabetes mellitus, or hypertension, all of which are likely to increase the level of oxidative/nitrosative stress. Taken together, these findings suggest that modulation of titin-based stiffness via cGMP-enhancing therapy could be a useful approach to correcting pathologically elevated LV diastolic stiffness, one of the primary characteristics of HFpEF in patients. Therefore, HFpEF treatment strategies might reasonably aim to treat comorbidities through the use of NO donors, phosphodiesterase-5 and 9 inhibitors, and antioxidants, the beneficial effects of which would also include a correction of titin-based myocardial stiffness.

\section{Histone deacetylases}

Oxidative stress is a major stimulator of epithelial cell function and can induce DNA damage and repair. During DNA repair, cells are prevented from entering $\mathrm{S}$ phase of the cell cycle (Clement et al. 2001). Many oxidants, including H2O2, can also induce enhanced release of inflammatory mediators from cells, a process that is associated with changes in histone acetylation (Ito et al. 2001). Histone acetylation and deacetylation are linked to cell cycle progression and correlate with repair and recombination events, as well as with gene transcription (Pazin and Kadonaga 1997; Tian et al. 2005). Histone acetylation promotes, while deacetylation inhibits, gene expression, via processes that are mediated by histone acetyltransferases and histone deacetylases (HDACs), respectively. Thioredoxin1-sensitive oxidation of the class II HDAC, HDAC4, has been implicated in $\alpha$-adrenergic receptor-induced cardiomyocyte hypertrophy (Ago et al. 2008). Class II 
HDACs normally inhibit the transcription of prohypertrophic myocyte enhancer factor-2-dependent genes. Intramolecular disulfide formation in HDACs has been shown to regulate HDAC localization and subsequent cardiomyocyte hypertrophy (Haworth et al. 2012). Nitration of HDAC2 following oxidative stress might also account for the reduced HDAC activity found in cells from patients with oxidative stressrelated diseases (Ito et al. 2001) and thus contribute to a worsening of inflammation (Ito et al. 2004).

\section{Calcium calmodulin-dependent kinase II}

Calcium calmodulin-dependent kinase II (CaMKII) phosphorylates several cardiac calcium handling and myofilament proteins to modulate excitation-contraction coupling, apoptosis, and gene transcription (Backs et al. 2006; Maier and Bers 2007; Toischer et al. 2010). CaMKII isoforms show increased expression/activity in failing human hearts and in animal models of cardiac hypertrophy (Anderson et al. 2011;

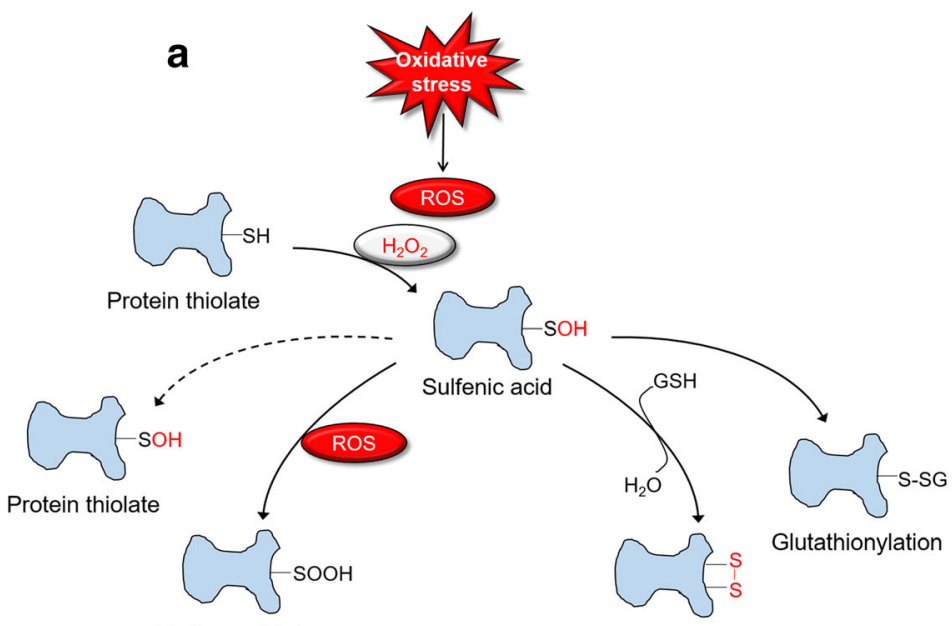

Further oxidation

Disulfide bond formation

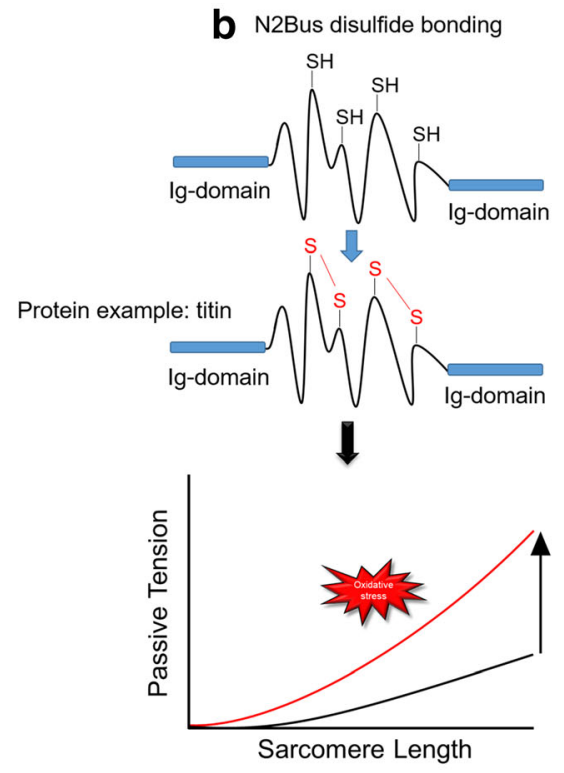

Fig. 3 Thiol modifications of proteins and mechanisms of titin-based passive tension modulation by oxidative stress-induced titin modifications. A Formation of sulfenic acid from the reaction of $\mathrm{H}_{2} \mathrm{O}_{2}$ with protein thiolates. This formation leads to different protein modifications. In proteins without a second sulfhydryl, the sulfenic acid (-SOH) may be stabilized or will generate oxidized sulfinic $(-\mathrm{SOOH})$ and sulfonic acid derivatives due to its reaction with ROS. Otherwise, a disulfide bond can form between the two sulfur atoms (-S-S-). Lastly, the sulfenated cysteinyl residue can react with glutathione $(\mathrm{GSH})$, leading to a mixed d Ig domain disulfide bonding
and isomerisation
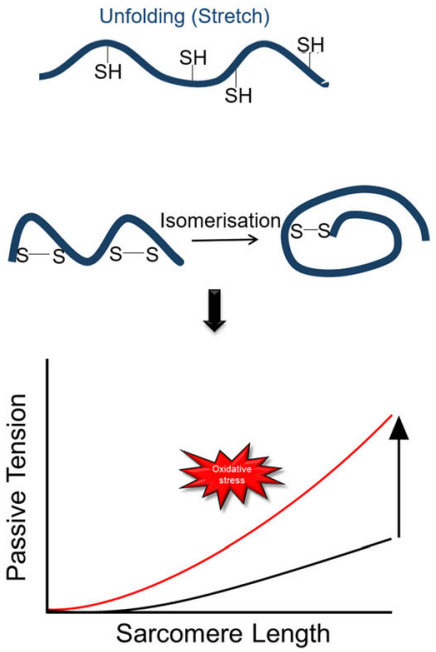

disulfide. B Formation of intramolecular disulfide bonds within the titinN2Bus when exposed to oxidative stress, which then increases titin-based stiffness in cardiomyocytes. C Ig domain unfolding due to sarcomere stretching causes exposure of hidden ("cryptic") cysteines in Ig domains, which can become $S$-glutathionylated under oxidative conditions. This modification prevents Ig domain refolding, resulting in decreased titinbased stiffness. D Isomerization of disulfide bonds of the cysteine triad in titin Ig domains can occur under oxidative conditions. This modification leads to increased titin based stiffness 
Swaminathan et al. 2012; Toischer et al. 2010). Overexpression of CaMKII $\delta \mathrm{C}$ in mouse myocardium is associated with massive cardiac hypertrophy and induces dilated cardiomyopathy and premature death (Zhang et al. 2003). CaMKII activity and expression are also elevated in cardiac injury models, including myocardial infarction (MI) (Singh et al. 2009; Zhang et al. 2005), and in ischemia-reperfusion (I/R) injury (Salas et al. 2010; Vila-Petroff et al. 2007). Knocking out the CaMKII $\delta$ isoform in mice attenuates pathological cardiac hypertrophy and remodeling in response to pressure overload (Backs et al. 2009; Ling et al. 2009). CaMKII is a multimeric complex with multiple catalytic domains, therefore providing a basis for a graded calcium response (Hamdani et al. 2013c; Hudmon and Schulman 2002). Calcium-dependent activation upon oxidative stress leads to intersubunit autophosphorylation at Thr-287 within the autoinhibitory domain, preventing its reassociation with the catalytic domain and sustaining kinase activity. CaMKII activity is enhanced upon exposure to oxidative stress, as shown by the redox-active regulatory domain methionine residues (Met-281 and 282) that sustain CaMKII activity even in the absence of calcium calmodulin. Chronic angiotensin II treatment and/or myocardial infarction has been shown to promote oxidation and apoptosis (Erickson et al. 2008), but these effects were attenuated in transgenic mice expressing a CaMKII inhibitory peptide or in mice expressing Met281/ 282Val CaMKII. Furthermore, overexpression of CaMKII inhibitory peptide reduces CaMKII oxidation and blocks the pathological consequences of aldosterone and angiotensin II in myocardium (He et al. 2011; Purohit et al. 2013). Methionine sulfoxide reductase reduces sulfoxidized methionine residues. Investigation of mice null for methionine sulfoxide reductase A found enhanced CaMKII oxidation, cell death, and heightened sensitivity to angiotensin II and infarction (Erickson et al. 2008). This strongly suggests that oxidation of CaMKII, via ROS produced by NADPH oxidase or in mitochondria, is directly detrimental to the heart. Elimination of either of these ROS pathways, via genetic knockout or targeted ROS scavenging, results in a reduction of CaMKII oxidation (Erickson et al. 2008; Luo et al. 2013). Overexpression of CaMKII in the heart disturbs calcium homeostasis and leads to HF and arrhythmias (Maier et al. 2003; Pabel et al. 2020; Zhang et al. 2003). Taking these findings as a whole, we suggest that oxidative activation of CaMKII plays a critical role in the pathogenesis of cardiac disease.

\section{Glyceraldehyde 3-phosphate dehydrogenase}

Glyceraldehyde-3-phosphate dehydrogenase (GAPDH) is a conserved enzyme that controls glucose flux through the canonical Embden-Meyerhof glycolytic pathway (J Biol, 2007, vol. 64 pg. 10). It also mediates cell death via nuclear translocation under conditions of oxidative stress. GAPDH is a glycolytic enzyme that is responsible for the sixth step of glycolysis (Nicholls et al. 2012) and is a multifunctional protein with additional functions, including transcriptional (Zheng et al. 2003) and posttranscriptional gene regulation (Rodríguez-Pascual et al. 2008), and intracellular membrane trafficking (Chuang et al. 2005; Hara et al. 2006; Tisdale 2001). Its catalytic thiol is subject to reversible and irreversible forms of inhibitory oxidation, which have also been observed during myocardial ischemia-reperfusion (Blaustein et al. 1989; Eaton et al. 2002a). The protein undergoes S nitrosylation by NO, which triggers nuclear translocation and apoptosis (Hara et al. 2005; Sen et al. 2008). Another redox-regulated function of GAPDH is to control mRNA stabilization (Rodríguez-Pascual et al. 2008). GAPDH binds the 3 '-untranslated region of endothelin-1 mRNA and enhances its degradation through destabilization. Oxidative stress alters the binding of GAPDH to this mRNA and thus its capacity to modulate endothelin-1 expression. This phenomenon occurs through specific $S$-glutathionylation of the catalytically active residue cysteine 152 (Rodríguez-Pascual et al. 2008), which also modulates the metabolic activity of GAPDH in an oxidative stress-dependent fashion (Jeong et al. 2011). GAPDH also undergoes $\mathrm{NAD}^{+}$covalent linkage upon $S$-nitrosylation (Mohr et al. 1996), nitroalkylation by nitrated fatty acids (Batthyany et al. 2006), and $S$-glutathionylation by glutathione or even by NO (Mohr et al. 1999), in addition to extensive oxidation by peroxynitrite or $\mathrm{H}_{2} \mathrm{O}_{2}$ (Little and O'Brien 1969; Souza and Radi 1998). These results suggest that GAPDH exerts other functions beyond glycolysis and that oxidative modifications of GAPDH regulate its cellular functions by changing its interactions with other proteins.

\section{Oxidation of titin and its effect on cardiomyocyte stiffness}

Oxidative stress, such as that seen in myocardial ischemiareperfusion damage, obesity, or diabetes mellitus, impairs LV diastolic function, which can be independently modulated through cardiomyocyte and especially titin-based stiffness. Interestingly, the stiffness of titin can also be directly affected by oxidative stress, acting via several mechanisms.

First, oxidizing conditions promote the formation of disulfide bridges within the disordered N2-Bus element of cardiac titin. The human N2-Bus contains 6 cysteines, which can form $\leq 3$ disulfide bonds. Because $\mathrm{S}-\mathrm{S}$ bridges are covalent bonds, the internally cross-linked N2-Bus loses much of its extensibility, resulting in elevated cardiomyocyte passive tension (Fig. 3) (Grützner et al. 2009; Linke and Hamdani 2014).

A second direct oxidative stress-related mechanism, recently elucidated, targets the Ig domains, which constitute the majority of elastic titin. If I-band Ig domains become unfolded, for example due to increased strain on the sarcomeres, 
they expose cryptic cysteines which now become accessible to disulfide bonding or $S$-glutathionylation under oxidizing conditions (Fig. 3) (Alegre-Cebollada et al. 2014). Importantly, the unfolded titin-Ig domains almost exclusively form mixed disulfides with glutathione, which weakens the mechanical stability of these domains and prevents their refolding. $S$ Glutathionylation substantially reduces the passive tension of stretched human cardiomyocytes incubated with oxidized glutathione, and the effect is reversible upon incubation with reduced glutathione (Alegre-Cebollada et al. 2014). An interesting implication of this novel mechanism of regulating titin elasticity is that it opens the possibility that titin-Ig domains represent mechanosensors that respond to oxidative stresscoupled myocyte stretch with reversible mechanical softening, which could well be the origin of altered mechanochemical signaling in stressed cardiomyocytes.

A third mechanism involves $S$-sulfenylation of cryptic cysteines, a modification that has been shown to cause titin stiffening (Fig. 3) (Beedle et al. 2016). This modification is wellknown as a trigger of protein misfolding, in addition to potentially leading to the formation of a disulfide bond that protects the Ig domain fold. The intramolecular S-S bond leads to stiffening of the Ig domain segments (Ainavarapu et al. 2007; Kosuri et al. 2012), which presumably leads to increased titin-based passive stiffness in a reversible manner, depending on the redox state of the cardiomyocyte.

Finally, another mechanism of stiffness modulation under oxidative stress is the formation and isomerization of disulfide bonds in unfolded titin Ig domains. Ig domains contain many conserved cysteines which potentially oxidize under oxidative stress conditions, form S-S bridges, and isomerize (Fig. 3) (Alegre-Cebollada et al. 2011; Giganti et al. 2018; Solsona et al. 2014). This disulfide bond formation and isomerization prevents further unfolding of the Ig domain, presumably leading to increased titin-based passive tension. All of these findings point to the important role of titin oxidation in regulation of cardiomyocyte stiffness in vivo and further suggest that the correction of titin oxidation may be relevant in diseased hearts characterized by increased oxidative stress, with correction leading to reduced pathological cardiomyocyte stiffness and normalized diastolic function.

\section{Oxidative stress-related endothelial dysfunction in cardiovascular disease}

Endothelial dysfunction is a pathological condition characterized by loss of balance in all major endothelial mechanisms (Fig. 4). The condition has been implicated in the pathophysiology of various cardiovascular diseases, including chronic HF (Endemann and Schiffrin 2004). Endothelial dysfunction is caused by inflammation, free radicals, and cytokines, acting via oxidized low-density lipoproteins that increase the expression of adhesion molecules in the endothelium, facilitating monocyte infiltration into the subendothelial space (Couillard et al. 2005; Janabi et al. 2000). Endothelial dysfunction plays an important role in the excessive systemic vasoconstriction and reduced peripheral tissue perfusion observed in chronic HF, as worsening vasoconstriction augments myocardial damage. Decreased coronary endothelium-dependent vasodilation impairs myocardial perfusion, reduces coronary flow, and worsens ventricular function. The decreased cardiac output observed in HF patients culminates in endothelial shear stress that stimulates eNOS expression. In HF, the downregulation of eNOS expression results in less NO production and hence diminished flowmediated vasodilation, giving place to concomitant vasoconstriction. Experimental models have shown that oxidative stress significantly stimulates the progression of endothelial dysfunction (Heitzer et al. 2001). Endothelial inflammatory activation in primates developing diet-induced obesity, evident from adhesion molecule expression, appears to be the earliest manifestation of vascular damage (Chadderdon et al. 2014). Endothelial inflammatory activation is associated with microalbuminuria, which is in turn associated with diastolic dysfunction and predicts HFpEF development (Brouwers et al. 2013). In HFpEF, endothelial dysfunction is linked to the worsening of symptoms (Borlaug et al. 2010), functional capacity (Borlaug et al. 2010), and precapillary pulmonary hypertension (Farrero et al. 2014). In general, comorbidities lead to systemic inflammation and increased oxidative stress, triggering endothelial and cardiomyocyte dysfunction and so contributing to the development of HF and HFpEF (Franssen et al. 2016; Kolijn et al. 2020b). Inflammation and oxidative stress in HFpEF patients and HFpEF rats were accompanied by impaired eNOS phosphorylation and NO bioavailability in the myocardium, and specifically in cardiomyocytes (Kolijn et al. 2020b). Previous work has indicated that both are likely to be the primary underlying causes of the abnormal cardiomyocyte stiffness that results from titin hypophosphorylation (Franssen et al. 2016; Hamdani et al. 2013a; b; 2014; van Heerebeek et al. 2008). The reduced production of $\mathrm{NO}$ and sGC could be a result of increased $\mathrm{H}_{2} \mathrm{O}_{2}$ and 3-nitrotyrosine, as shown previously (Herwig et al. 2020; Kolijn et al. 2020b), and may be due to the uncoupling of eNOS, thereby switching the eNOS dimer to a superoxide anion-generating monomer (Franssen et al. 2016; Kolijn et al. 2020b).

In HF, both cardiomyocyte and endothelial cells contribute to cardiac dysfunction. Systemic inflammation induces inflammatory activation of the endothelium of myocardial microcirculation. This leads to enhanced endothelial expression of adhesion molecules such as ICAM-1, VCAM, and Eselectin (Fig. 4) (Franssen et al. 2016; Kolijn et al. 2020b). As a result of inflammatory activation, NOX2 is upregulated in endothelial cells, leading to oxidative stress, increased levels of $\mathrm{H}_{2} \mathrm{O}_{2}$, uncoupling of eNOS, decreased $\mathrm{NO}$ 
bioavailability, and formation of 3-nitrotyrosine and thereby endothelial dysfunction and subsequent cardiac dysfunction (Franssen et al. 2016; Kolijn et al. 2020b). On the other hand, in cardiomyocytes, increased oxidative stress leads to the generation of $\mathrm{H} 2 \mathrm{O} 2$ and thereby decreased $\mathrm{NO}$ bioavailability, which in turn leads to less stimulation of sGC, reduced formation of cGMP, and diminished PKG activity (Kolijn et al. 2020b). A lack of PKG activity is associated with decreased titin phosphorylation and increased passive stiffness of cardiomyocytes. Due to a low cGMP concentration, the latter pathway fails to compensate for the decreased NO bioavailability. Ultimately, this leads to chronic cardiomyocyte dysfunction and thereby cardiac dysfunction.

\section{Alterations in stress signaling pathways}

Biomechanical stress as a result of hypoxia, hypertension, and other forms of myocardial injury leads to a decline in myocardium function and thereby triggers signals to compensate via hypertrophy. Cardiac hypertrophy, in its early stages, is part of a compensatory response to external stressors, including mechanical loading and oxidative stresses (Linke and Hamdani 2014). The onset of cardiac hypertrophy can be a beneficial response that maintains or augments cardiac output without adverse pathology. However, when stressors persist, compensatory hypertrophy can evolve into a decompensated state with profound changes in gene expression programs, contractile dysfunction, and extracellular remodeling. A transition can occur during the dilation of the heart and thinning of the walls of the ventricular chamber.

Hyperglycemia in diabetes causes alterations in membrane and metabolic and biochemical functions that lead to contractile dysfunction and thereby cardiac dysfunction. Hyperglycemia also results in the generation of ROS, ultimately leading to increased oxidative stress in a variety of tissues. Consequently, this will lead to the activation of stress-sensitive intracellular signaling pathways once there is a redox imbalance in the cell.

One major intracellular target of hyperglycemia and oxidative stress is nuclear factor- $\mathrm{KB}(\mathrm{NF}-\mathrm{kB})$ (Barnes and Karin 1997; Mohamed et al. 1999; Tak and Firestein 2001). $\mathrm{NF}-\mathrm{KB}$ can be activated by a wide array of exogenous and endogenous stimuli including hyperglycemia, elevated free fatty acids, ROS, TNF- $\alpha$, IL- $1 \beta$, and other proinflammatory cytokines, advanced glycosylation endproduct-binding and receptor for AGE, p38 MAPK, DNA damage, viral infection, and ultraviolet irradiation (Barnes and Karin 1997). In addition to its role in apoptosis, NF-kB plays a crucial role in mediating immune and inflammatory responses. Modifications in NF- $\mathrm{kB}$ signaling are associated with various heart diseases. The c-Jun $\mathrm{NH}(2)$-terminal kinases (JNK) and p38 MAPKs are members of the extensive superfamily of MAP serine/threonine protein kinases and can be a

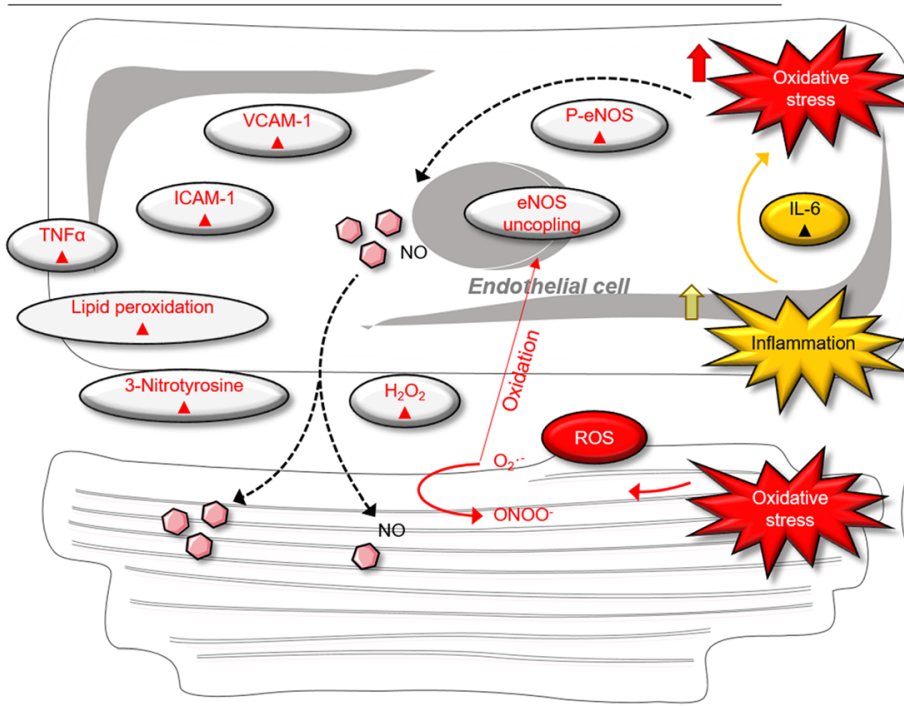

b Healthy Heart

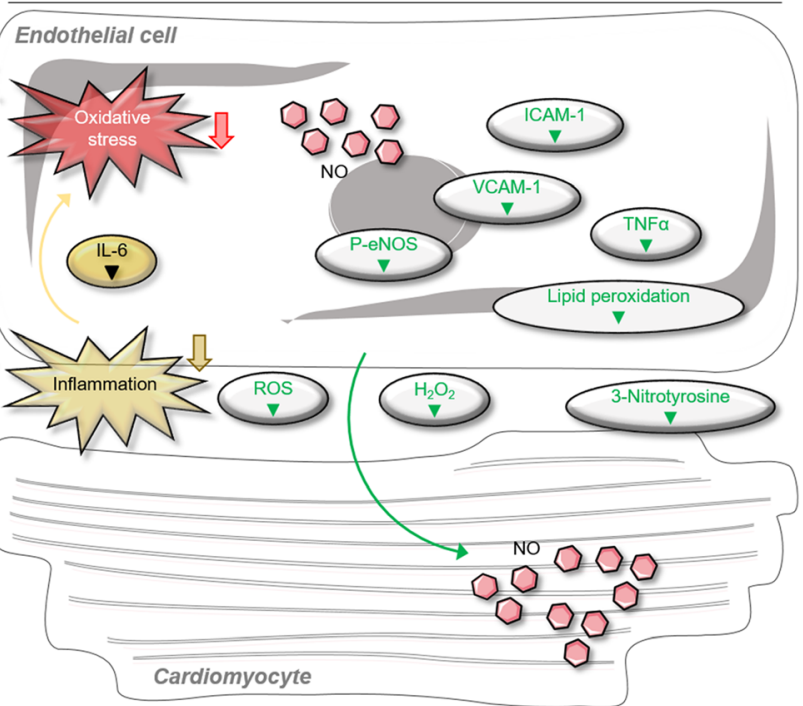

(green arrow pointing upwards means increase and green arrow pointing down means decrease). Abbreviations: $\mathrm{H}_{2} \mathrm{O}_{2}$, hydrogen peroxide; ICAM1, intercellular cell adhesion molecule-1; IL-6, interleukin-6; NO, nitric oxide; NOX2, NADPH phagocyte oxidase isoform; ONOO-, peroxynitrite; ROS, reactive oxygen species; sGC, soluble guanylyl cyclase; TNF- $\alpha$, tumor necrosis factor-alpha; VCAM-1, vascular cell adhesion molecule-1; P-eNOS, phospho-endothelial nitric oxide synthase
Fig. 4 Scheme for the signaling pathways of endothelial cell in diseased heart under oxidative (right) and healthy (left) conditions. A Represents a heart under oxidative condition with impaired endothelial function via increased inflammatory cytokines and oxidative stress (red arrow pointing upwards means increase and red arrow pointing down means decrease). B Represents a healthy condition showing a normal endothelial function via normal/low inflammatory cytokines and oxidative stress 
activated and/or stimulated through different stress-inducing stimuli, including oxidative stress, ROS, hyperglycemia, osmotic stress, heat shock, and pro-inflammatory cytokines ("stress-activated kinases") (Tibbles and Woodgett 1999). These kinases are activated in response to hyperglycemia and diabetes and are involved in apoptosis, which can be suppressed by antioxidant vitamin C (Ho et al. 2000). Chronic activation of the p38 MAPK pathway is often associated with disease pathology, including inflammation, ischemia/reperfusion injury, infectious disease, and neuronal disease (Obata et al. 2000).

In addition, extracellular signal-regulated kinase (ERK) 1 and 2 cascades are markedly activated in cardiomyocytes by virtually all hypertrophic stimuli, inhibition of the cascade suppresses at least some aspects of the hypertrophic response, and constitutive activation of the pathway produces compensated cardiac hypertrophy in transgenic mice (Bueno and Molkentin 2002; Sugden and Clerk 1998a). However, while the ERK1/2 cascade is implicated in promoting cardiomyocyte hypertrophy, it can also be activated in cardiomyocytes by cellular stresses, including $\mathrm{H}_{2} \mathrm{O}_{2}$, which induce cardiac myocyte apoptosis. Hence, ROS, redox signaling, and oxidative stress all contribute to both physiological and pathological conditions.

\section{Therapeutic implications}

The current treatment options for many forms of heart disease in particular for HFpEF patients are very limited and no drug has yet been shown to improve cardiac or specifically diastolic function in these patients. Many of the tested compounds were ineffective in reducing morbidity and mortality although in many cases proven to be effective for the treatment of HFrEF. Accordingly, several clinical trials have failed to show that any of these proposed drugs have positive effects in HFpEF patients. Patient management is presently limited to amelioration of symptoms and the treatment of common comorbidities such as hypertension, diabetes, obesity, and atrial fibrillation. Some trials such as the recent PARAGON-HF trial that investigated the effects of sacubitril/valsartan in patients with HFrEF showed evidence of a very heterogeneous response to treatment (Solomon et al. 2019). Potential benefit was detected only in some subgroups, such as women and patients with an ejection fraction below the median in the direction towards HF with mid-range EF. These results strongly imply that one size might not fit all in heart failure and in particular HFpEF (ClinicalTrials.gov Identifier: NCT0192071). Many studies showed suppression of several signaling pathways and in particular the cGMP-PKG pathway in HFpEF patients and animal models of HFpEF. This reduction is possibly due to inflammation and oxidative stress making it a suggestive treatment target option for these patients.
However, as many heart diseases are characterized by increased inflammation and oxidative stress, one may think that targeting both could be a treatment option for many subgroups. Indeed, our recent work suggested that increased oxidative stress and inflammation may play a major role in the deterioration of LV diastolic function, as we showed that NOsGC-cGMP-PKG signaling is reduced in HFpEF patients and in an HFpEF animal model (Kolijn et al. 2020a; b). Increased inflammation and oxidative stress led to impaired cardiomyocyte and endothelial function and thereby to diastolic dysfunction. This latest was associated with disarranged a couple of signaling pathways and protein modifications (Kolijn et al. 2020a; b). All of which further suggest that increased oxidative stress and inflammation may exacerbate the pathophysiology of different heart diseases and specifically in HFpEF. Both acute treatments with the sodium-glucose cotransporter 2 (SGLT2) inhibitor empagliflozin and sGC activator showed antioxidant and anti-inflammatory properties when the myocardium of $\mathrm{HF}$ and $\mathrm{HFpEF}$ patients and rats were treated (Kolijn et al. 2020b). Empagliflozin is an inhibitor of the Na-dependent glucose cotransporter 2 (SGLT2) and is clinically approved as an oral antidiabetic drug. By inhibiting SGLT2 in the proximal tubule of the kidney, empagliflozin reduces the reuptake of glucose and $\mathrm{Na}$ and thereby lowers blood glucose. In the EMPA-REG OUTCOME trial, empagliflozin was evaluated for its cardiovascular safety. The results showed that empagliflozin reduced cardiovascular mortality, all-cause mortality, and heart failure (HF) hospitalization rates. Interestingly, the effects of empagliflozin in the EMPA-REG OUTCOME trial on HF hospitalization and mortality occurred within only a few months after initiation of treatment, suggesting the mechanisms are independent of long-acting secondary risk factors. This is supported by recent clinical data showing that empagliflozin exerts the same beneficial cardiovascular effects after adjustment for cardiovascular risk factors (blood pressure, low-density lipoprotein cholesterol, and HbA1c) (Fitchett et al. 2019; Neal et al. 2017; Wiviott et al. 2019; Zinman et al. 2015). sGC activity when the heme iron is oxidized $(\mathrm{Fe} 3+)$ on the heme group is missing (Sandner et al. 2019; Stasch et al. 2001; 2011) and increase NO. Both empagliflozin and the sGC activator improved cardiomyocyte function via improved titin and other myofilament protein phosphorylation, an effect likely due to improved signaling pathways including the pathway NO-sGCcGMP-PKG and the hypertrophic pathways mediated by CaMKII, PKC, and ERK2, in addition to the PKA pathway (Kolijn et al. 2020a). Moreover, treatment with both drugs reduced pathologically elevated pro-inflammatory cytokines in human HFpEF myocardium as well as in HFpEF rats and thereby improved endothelial function. This improvement was accompanied with diminished increased levels of myocardial and cardiomyocyte oxidative stress in human and rats (Kolijn et al. 2020a; b). Previous work suggested that 
comorbidities lead to systemic inflammation and increased oxidative stress, which triggers endothelial and cardiomyocyte dysfunction; it is not surprising that interventions that reduce inflammation are being explored as potential treatment in heart failure. Other studies also demonstrated that empagliflozin is associated with reduced inflammation and reduced activation of the nucleotide-binding domain-like 81 receptor protein 3 inflammation in liver and plasma in type 1 and 2 diabetes (Marx and McGuire 2016; Tahara et al. 2013; 2014) inflammasome in the kidney (Benetti et al. 2016) and heart (Lee et al. 2017). Previous work in HFpEF rats and human HFpEF reported diminished oxidative parameters upon empagliflozin (Kolijn et al. 2020b). Several studies showed that increased NO can suppress inflammation and regulates the synthesis of pro-inflammatory cytokines, as NO donors and L-arginine attenuate the expression of many proinflammatory cytokines (De Caterina et al. 1995; Spiecker et al. 1998); and supported by this the outcome of the SGLT2 inhibitors and the sGC activator in suppressing inflammation and oxidative stress, perhaps all via boosting the NO-sGC-cGMP-PKG pathway. Most importantly, these effects occur in the absence of any negative inotropy (Pabel et al. 2018). In the light of recent clinical endpoint trials investigating the effects of SGLT2-inhibitors in high-risk patients, a subgroup analysis of patients with $\mathrm{HFpEF}$, which has not yet been available for these trials, would be of particular interest. However, according to the inclusion criteria of the EMPA-REG OUTCOME (Zinman et al. 2015), DECLARE-TIMI 58 (Wiviott et al. 2019), and the CANVAS study (Neal et al. 2017), a not inconsiderable number of patients should suffer from HFpEF because either the presence of established cardiovascular diseases or a combination of risk factors such as e.g. dyslipidemia or arterial hypertension in many cases combined with diabetes was inclusion criteria. The latter combination suggests a not inconsiderable proportion of HFpEF patients in the collective as a whole. Since adequate and therefore well-characterized subgroup analyses are not to be expected in this regard, the results of the DELIVER and EMPEROR-Preserved studies must be awaited, which specifically examine the influence of SGLT2 inhibitors on hard endpoints in HFpEF patients. Finally, another potential treatment for heart failure patients with increased oxidative stress and inflammation would be theoretically "a cocktail drug," which may combine different targets in one. As many pro-inflammatory cytokines and oxidative parameters are increased in HF, one may suggest to suppress all of them together using a multiple anti-inflammatory drug and/or a multiple antioxidant drug. In the past, the potential benefit of antioxidative strategies for treating HF has already been postulated. However, while agents with antioxidative properties i.e. like vitamin $\mathrm{C}$ or vitamin $\mathrm{E}$ showed beneficial effects in vitro, clinical trials largely failed in translating those effects into an improvement of clinical endpoints (Farías et al.
2017; Keith et al. 2001; Myung et al. 2013). A potential limitation could be that the effective concentration of the respective antioxidative agents in the heart has not been reached upon in vivo application (Farías et al. 2017). Therefore, targeting specific regulatory proteins of the proinflammatory and oxidative signaling cascades in cardiac disease might be a valuable approach to reduce adverse remodeling mediated by myocardial inflammation and oxidative stress. However, as individuals with HFpEF still represent a very heterogeneous collective, one may consider to establish more specific diagnostic subgroups in order to establish more precise therapeutic approaches. In this case, different combinations with the existing drugs may be more appropriate and effective for each sub-group so far.

\section{Conclusion}

It remains very critical to understand the complex interactions of oxidative and nitrosative stress with pro-inflammatory mechanisms, metabolic dysfunction, signaling pathways, and the redox modification of proteins characteristic of heart failure to design novel approaches to therapeutic strategies for each heart failure phenotype.

Funding information Open Access funding provided by Projekt DEAL. This work was supported by NH and is funded by DFG (HA 7512/2-1) and FoRUM-Projekt (F765-13, F808N-14, and F882R-2017).

\section{Compliance with ethical standards}

Conflict of interest The authors declare that they have no conflict of interest.

Open Access This article is licensed under a Creative Commons Attribution 4.0 International License, which permits use, sharing, adaptation, distribution and reproduction in any medium or format, as long as you give appropriate credit to the original author(s) and the source, provide a link to the Creative Commons licence, and indicate if changes were made. The images or other third party material in this article are included in the article's Creative Commons licence, unless indicated otherwise in a credit line to the material. If material is not included in the article's Creative Commons licence and your intended use is not permitted by statutory regulation or exceeds the permitted use, you will need to obtain permission directly from the copyright holder. To view a copy of this licence, visit http://creativecommons.org/licenses/by/4.0/.

\section{References}

Adachi T, Weisbrod RM, Pimentel DR, Ying J, Sharov VS, Schöneich C, Cohen RA (2004) S-Glutathiolation by peroxynitrite activates SERCA during arterial relaxation by nitric oxide. Nat Med 10: 1200-1207. https://doi.org/10.1038/nm1119

Ago T, Liu T, Zhai P et al (2008) A redox-dependent pathway for regulating class II HDACs and cardiac hypertrophy. Cell 133:978-993. https://doi.org/10.1016/j.cell.2008.04.041 
Ainavarapu SR, Brujic J, Huang HH et al (2007) Contour length and refolding rate of a small protein controlled by engineered disulfide bonds. Biophys J 92:225-233. https://doi.org/10.1529/biophysj. 106.091561

Alegre-Cebollada J, Kosuri P, Rivas-Pardo JA, Fernández JM (2011) Direct observation of disulfide isomerization in a single protein. Nat Chem 3:882-887. https://doi.org/10.1038/nchem.1155

Alegre-Cebollada J, Kosuri P, Giganti D et al (2014) S-glutathionylation of cryptic cysteines enhances titin elasticity by blocking protein folding. Cell 156:1235-1246. https://doi.org/10.1016/j.cell.2014. 01.056

Anderson ME, Brown JH, Bers DM (2011) CaMKII in myocardial hypertrophy and heart failure. J Mol Cell Cardiol 51:468-473. https:// doi.org/10.1016/j.yjmcc.2011.01.012

Arai M, Alpert NR, MacLennan DH, Barton P, Periasamy M (1993) Alterations in sarcoplasmic reticulum gene expression in human heart failure. A possible mechanism for alterations in systolic and diastolic properties of the failing myocardium. Circ Res 72:463469. https://doi.org/10.1161/01.res.72.2.463

Arstall MA, Sawyer DB, Fukazawa R, Kelly RA (1999) Cytokinemediated apoptosis in cardiac myocytes: the role of inducible nitric oxide synthase induction and peroxynitrite generation. Circ Res 85: 829-840. https://doi.org/10.1161/01.res.85.9.829

Aukrust P, Ueland T, Lien E et al (1999) Cytokine network in congestive heart failure secondary to ischemic or idiopathic dilated cardiomyopathy. Am J Cardiol 83:376-382. https://doi.org/10.1016/s00029149(98)00872-8

Backs J, Song K, Bezprozvannaya S, Chang S, Olson EN (2006) CaM kinase II selectively signals to histone deacetylase 4 during cardiomyocyte hypertrophy. J Clin Invest 116:1853-1864. https://doi.org/ $10.1172 /$ jci2 27438

Backs J, Backs T, Neef S et al (2009) The delta isoform of CaM kinase II is required for pathological cardiac hypertrophy and remodeling after pressure overload. Proc Natl Acad Sci U S A 106:23422347. https://doi.org/10.1073/pnas.0813013106

Balaban RS, Nemoto S, Finkel T (2005) Mitochondria, oxidants, and aging. Cell 120:483-495. https://doi.org/10.1016/j.cell.2005.02.001

Barnes PJ, Karin M (1997) Nuclear factor-kappaB: a pivotal transcription factor in chronic inflammatory diseases. N Engl J Med 336:10661071. https://doi.org/10.1056/nejm199704103361506

Batthyany C, Schopfer FJ, Baker PR et al (2006) Reversible posttranslational modification of proteins by nitrated fatty acids in vivo. J Biol Chem 281:20450-20463. https://doi.org/10.1074/ jbc.M602814200

Beedle AE, Lynham S, Garcia-Manyes S (2016) Protein S-sulfenylation is a fleeting molecular switch that regulates non-enzymatic oxidative folding. Nat Commun 7:12490. https://doi.org/10.1038/ ncomms 12490

Belch JJ, Bridges AB, Scott N, Chopra M (1991) Oxygen free radicals and congestive heart failure. Br Heart J 65:245-248. https://doi.org/ 10.1136/hrt.65.5.245

Bellinger AM, Reiken S, Carlson C et al (2009) Hypernitrosylated ryanodine receptor calcium release channels are leaky in dystrophic muscle. Nat Med 15:325-330. https://doi.org/10.1038/nm.1916

Benetti E, Mastrocola R, Vitarelli G et al (2016) Empagliflozin protects against diet-induced NLRP-3 inflammasome activation and lipid accumulation. J Pharmacol Exp Ther 359:45-53. https://doi.org/ 10.1124/jpet.116.235069

Bertero E, Maack C (2018) Calcium signaling and reactive oxygen species in mitochondria. Circ Res 122:1460-1478. https://doi.org/10. 1161/circresaha.118.310082

Bishu K, Hamdani N, Mohammed SF et al (2011) Sildenafil and B-type natriuretic peptide acutely phosphorylate titin and improve diastolic distensibility in vivo. Circulation 124:2882-2891. https://doi.org/ 10.1161/circulationaha.111.048520
Blaustein A, Deneke SM, Stolz RI, Baxter D, Healey N, Fanburg BL (1989) Myocardial glutathione depletion impairs recovery after short periods of ischemia. Circulation 80:1449-1457. https://doi. org/10.1161/01.cir.80.5.1449

Bode D, Lindner D, Schwarzl M et al (2019) The role of fibroblast cardiomyocyte interaction for atrial dysfunction in HFpEF and hypertensive heart disease. J Mol Cell Cardiol 131:53-65. https://doi. org/10.1016/j.yjmcc.2019.04.016

Borbély A, Falcao-Pires I, van Heerebeek L et al (2009) Hypophosphorylation of the stiff N2B titin isoform raises cardiomyocyte resting tension in failing human myocardium. Circ Res 104:780-786. https://doi.org/10.1161/circresaha.108.193326

Borkowski BJ, Cheema Y, Shahbaz AU, Bhattacharya SK, Weber KT (2011) Cation dyshomeostasis and cardiomyocyte necrosis: the Fleckenstein hypothesis revisited. Eur Heart J 32:1846-1853. https://doi.org/10.1093/eurheartj/ehr063

Borlaug BA, Kass DA (2006) Mechanisms of diastolic dysfunction in heart failure. Trends Cardiovasc Med 16:273-279. https://doi.org/ 10.1016/j.tcm.2006.05.003

Borlaug BA, Paulus WJ (2011) Heart failure with preserved ejection fraction: pathophysiology, diagnosis, and treatment. Eur Heart J 32:670-679. https://doi.org/10.1093/eurheartj/ehq426

Borlaug BA, Olson TP, Lam CS, Flood KS, Lerman A, Johnson BD, Redfield MM (2010) Global cardiovascular reserve dysfunction in heart failure with preserved ejection fraction. J Am Coll Cardiol 56: 845-854. https://doi.org/10.1016/j.jacc.2010.03.077

Breitkreuz M, Hamdani N (2015) A change of heart: oxidative stress in governing muscle function? Biophys Rev 7:321-341. https://doi. org/10.1007/s12551-015-0175-5

Brennan JP, Bardswell SC, Burgoyne JR et al (2006) Oxidant-induced activation of type I protein kinase a is mediated by RI subunit interprotein disulfide bond formation. J Biol Chem 281:2182721836. https://doi.org/10.1074/jbc.M603952200

Briasoulis A, Androulakis E, Christophides T, Tousoulis D (2016) The role of inflammation and cell death in the pathogenesis, progression and treatment of heart failure. Heart Fail Rev 21:169-176. https:// doi.org/10.1007/s10741-016-9533-Z

Brouwers FP, de Boer RA, van der Harst P et al (2013) Incidence and epidemiology of new onset heart failure with preserved vs. reduced ejection fraction in a community-based cohort: 11-year follow-up of PREVEND. Eur Heart J 34:1424-1431. https://doi.org/10.1093/ eurheartj/eht066

Bueno OF, Molkentin JD (2002) Involvement of extracellular signalregulated kinases $1 / 2$ in cardiac hypertrophy and cell death. Circ Res 91:776-781. https://doi.org/10.1161/01.res.0000038488. 38975.1a

Burchfield JS, Xie M, Hill JA (2013) Pathological ventricular remodeling: mechanisms: part 1 of 2 . Circulation 128:388-400. https://doi. org/10.1161/circulationaha.113.001878

Burgoyne JR, Madhani M, Cuello F et al (2007) Cysteine redox sensor in PKGIa enables oxidant-induced activation. Science 317:13931397. https://doi.org/10.1126/science.1144318

Burgoyne JR, Mongue-Din H, Eaton P, Shah AM (2012a) Redox signaling in cardiac physiology and pathology. Circ Res 111:1091-1106. https://doi.org/10.1161/circresaha.111.255216

Burgoyne JR, Prysyazhna O, Rudyk O, Eaton P (2012b) cGMPdependent activation of protein kinase $\mathrm{G}$ precludes disulfide activation: implications for blood pressure control. Hypertension 60: 1301-1308. https://doi.org/10.1161/hypertensionaha.112.198754

Burgoyne JR, Rudyk O, Cho HJ et al (2015) Deficient angiogenesis in redox-dead Cys17Ser PKARI $\alpha$ knock-in mice. Nat Commun 6: 7920. https://doi.org/10.1038/ncomms8920

Byrne JA, Grieve DJ, Cave AC, Shah AM (2003) Oxidative stress and heart failure. Arch Mal Coeur Vaiss 96:214-221

Campbell DL, Stamler JS, Strauss HC (1996) Redox modulation of Ltype calcium channels in ferret ventricular myocytes. Dual 
mechanism regulation by nitric oxide and S-nitrosothiols. J Gen Physiol 108:277-293. https://doi.org/10.1085/jgp.108.4.277

Canton M, Menazza S, Di Lisa F (2014) Oxidative stress in muscular dystrophy: from generic evidence to specific sources and targets. J Muscle Res Cell Motil 35:23-36. https://doi.org/10.1007/s10974014-9380-2

Chadderdon SM, Belcik JT, Bader L et al (2014) Proinflammatory endothelial activation detected by molecular imaging in obese nonhuman primates coincides with onset of insulin resistance and progressively increases with duration of insulin resistance. Circulation 129:471478. https://doi.org/10.1161/circulationaha.113.003645

Cheng TH, Shih NL, Chen SY, Wang DL, Chen JJ (1999) Reactive oxygen species modulate endothelin-I-induced c-fos gene expression in cardiomyocytes. Cardiovasc Res 41:654-662. https://doi. org/10.1016/s0008-6363(98)00275-2

Choudhary G, Dudley SC Jr (2002) Heart failure, oxidative stress, and ion channel modulation. Congest Heart Fail 8:148-155. https://doi.org/ 10.1111/j.1527-5299.2002.00716.x

Chuang DM, Hough C, Senatorov VV (2005) Glyceraldehyde-3phosphate dehydrogenase, apoptosis, and neurodegenerative diseases. Annu Rev Pharmacol Toxicol 45:269-290. https://doi.org/ 10.1146/annurev.pharmtox.45.120403.095902

Clement A, Henrion-Caude A, Besnard V, Corroyer S (2001) Role of cyclins in epithelial response to oxidants. Am J Respir Crit Care Med 164:S81-S84. https://doi.org/10.1164/ajrccm.164. supplement_2.2106069

Collier P, Watson CJ, Voon V et al (2011) Can emerging biomarkers of myocardial remodelling identify asymptomatic hypertensive patients at risk for diastolic dysfunction and diastolic heart failure? Eur J Heart Fail 13:1087-1095. https://doi.org/10.1093/eurjhf/ hfr079

Communal C, Singh K, Pimentel DR, Colucci WS (1998) Norepinephrine stimulates apoptosis in adult rat ventricular myocytes by activation of the beta-adrenergic pathway. Circulation 98:1329-1334. https://doi.org/10.1161/01.cir.98.13. 1329

Cosentino F, Lüscher TF (1997) Endothelial function in coronary artery disease. Cardiologia 42:1221-1227

Couillard C, Ruel G, Archer WR et al (2005) Circulating levels of oxidative stress markers and endothelial adhesion molecules in men with abdominal obesity. J Clin Endocrinol Metab 90:6454-6459. https://doi.org/10.1210/jc.2004-2438

de Almeida A, de Almeida Rezende MS, Dantas SH et al (2020) Unveiling the role of inflammation and oxidative stress on agerelated cardiovascular diseases. Oxidative Med Cell Longev 2020: 1954398. https://doi.org/10.1155/2020/1954398

De Caterina R, Libby P, Peng HB et al (1995) Nitric oxide decreases cytokine-induced endothelial activation. Nitric oxide selectively reduces endothelial expression of adhesion molecules and proinflammatory cytokines. J Clin Invest 96:60-68. https://doi.org/10.1172/ jci1 18074

de Piña MZ, Vázquez-Meza H, Pardo JP, Rendón JL, Villalobos-Molina R, Riveros-Rosas H, Piña E (2008) Signaling the signal, cyclic AMP-dependent protein kinase inhibition by insulin-formed $\mathrm{H} 2 \mathrm{O} 2$ and reactivation by thioredoxin. J Biol Chem 283:12373-12386. https://doi.org/10.1074/jbc.M706832200

Dewald O, Zymek P, Winkelmann K et al (2005) CCL2/monocyte chemoattractant protein-1 regulates inflammatory responses critical to healing myocardial infarcts. Circ Res 96:881-889. https://doi.org/ 10.1161/01.RES.0000163017.13772.3a

Dick SA, Epelman S (2016) Chronic heart failure and inflammation: what do we really know? Circ Res 119:159-176. https://doi.org/10.1161/ circresaha.116.308030

Disatnik MH, Dhawan J, Yu Y, Beal MF, Whirl MM, Franco AA, Rando TA (1998) Evidence of oxidative stress in mdx mouse muscle: studies of the pre-necrotic state. J Neurol Sci 161:77-84. https:// doi.org/10.1016/s0022-510x(98)00258-5

Diwan A, Tran T, Misra A, Mann DL (2003) Inflammatory mediators and the failing heart: a translational approach. Curr Mol Med 3:161-182. https://doi.org/10.2174/1566524033361537

Dostalek M, Hardy KD, Milne GL et al (2008) Development of oxidative stress by cytochrome $\mathrm{P} 450$ induction in rodents is selective for barbiturates and related to loss of pyridine nucleotide-dependent protective systems. J Biol Chem 283:17147-17157. https://doi.org/10. 1074/jbc.M802447200

Durham WJ, Aracena-Parks P, Long C et al (2008) RyR1 S-nitrosylation underlies environmental heat stroke and sudden death in Y522S RyR1 knockin mice. Cell 133:53-65. https://doi.org/10.1016/j.cell. 2008.02.042

Eaton P, Byers HL, Leeds N, Ward MA, Shattock MJ (2002a) Detection, quantitation, purification, and identification of cardiac proteins Sthiolated during ischemia and reperfusion. J Biol Chem 277:98069811. https://doi.org/10.1074/jbc.M111454200

Eaton P, Wright N, Hearse DJ, Shattock MJ (2002b) Glyceraldehyde phosphate dehydrogenase oxidation during cardiac ischemia and reperfusion. J Mol Cell Cardiol 34:1549-1560. https://doi.org/10. 1006/jmcc. 2002.2108

Endemann DH, Schiffrin EL (2004) Endothelial dysfunction. J Am Soc Nephrol 15:1983-1992. https://doi.org/10.1097/01.asn. 0000132474.50966.da

Erickson JR, Joiner ML, Guan X et al (2008) A dynamic pathway for calcium-independent activation of CaMKII by methionine oxidation. Cell 133:462-474. https://doi.org/10.1016/j.cell.2008.02.048

Falkenham A, de Antueno R, Rosin N, Betsch D, Lee TD, Duncan R, Légaré JF (2015) Nonclassical resident macrophages are important determinants in the development of myocardial fibrosis. Am J Pathol 185:927-942. https://doi.org/10.1016/j.ajpath.2014.11.027

Farías JG, Molina VM, Carrasco RA, Zepeda AB, Figueroa E, Letelier P, Castillo RL (2017) Antioxidant therapeutic strategies for cardiovascular conditions associated with oxidative stress. Nutrients:9. https:// doi.org/10.3390/nu9090966

Farrero M, Blanco I, Batlle M et al (2014) Pulmonary hypertension is related to peripheral endothelial dysfunction in heart failure with preserved ejection fraction. Circ Heart Fail 7:791-798. https://doi. org/10.1161/circheartfailure.113.000942

Finkel T (1999) Signal transduction by reactive oxygen species in nonphagocytic cells. J Leukoc Biol 65:337-340. https://doi.org/10. 1002/jlb.65.3.337

Finkel T (2012) Signal transduction by mitochondrial oxidants. J Biol Chem 287:4434 4440. https://doi.org/10.1074/jbc.R111.271999

Finkel MS, Oddis CV, Jacob TD, Watkins SC, Hattler BG, Simmons RL (1992) Negative inotropic effects of cytokines on the heart mediated by nitric oxide. Science 257:387-389. https://doi.org/10.1126/ science. 1631560

Fitchett D, Inzucchi SE, Cannon CP et al (2019) Empagliflozin reduced mortality and hospitalization for heart failure across the spectrum of cardiovascular risk in the EMPA-REG OUTCOME trial. Circulation 139:1384-1395. https://doi.org/10.1161/circulationaha. 118.037778

Franssen C, Chen S, Unger A et al (2016) Myocardial microvascular inflammatory endothelial activation in heart failure with preserved ejection fraction. JACC Heart Fail 4:312-324. https://doi.org/10. 1016/j.jchf.2015.10.007

Frantz S, Hofmann U, Fraccarollo D et al (2013) Monocytes/ macrophages prevent healing defects and left ventricular thrombus formation after myocardial infarction. FASEB J 27:871-881. https:// doi.org/10.1096/fj.12-214049

Gao WD, Liu Y, Marban E (1996) Selective effects of oxygen free radicals on excitation-contraction coupling in ventricular muscle. Implications for the mechanism of stunned myocardium. 
Circulation 94:2597-2604. https://doi.org/10.1161/01.cir.94.10. 2597

Gaponenko V, Abusamhadneh E, Abbott MB et al (1999) Effects of troponin I phosphorylation on conformational exchange in the regulatory domain of cardiac troponin C. J Biol Chem 274:1668116684. https://doi.org/10.1074/jbc.274.24.16681

Giganti D, Yan K, Badilla CL, Fernandez JM, Alegre-Cebollada J (2018) Disulfide isomerization reactions in titin immunoglobulin domains enable a mode of protein elasticity. Nat Commun 9:185. https://doi. org/10.1038/s41467-017-02528-7

Giugliano D, Ceriello A, Paolisso G (1996) Oxidative stress and diabetic vascular complications. Diabetes Care 19:257-267. https://doi.org/ 10.2337/diacare.19.3.257

Glezeva N, Baugh JA (2014) Role of inflammation in the pathogenesis of heart failure with preserved ejection fraction and its potential as a therapeutic target. Heart Fail Rev 19:681-694. https://doi.org/10. 1007/s10741-013-9405-8

Glezeva N, Voon V, Watson C, Horgan S, McDonald K, Ledwidge M, Baugh J (2015) Exaggerated inflammation and monocytosis associate with diastolic dysfunction in heart failure with preserved ejection fraction: evidence of M2 macrophage activation in disease pathogenesis. J Card Fail 21:167-177. https://doi.org/10.1016/j.cardfail. 2014.11.004

Goldhaber JI, Qayyum MS (2000) Oxygen free radicals and excitationcontraction coupling. Antioxid Redox Signal 2:55-64. https://doi. org/10.1089/ars.2000.2.1-55

Goldhaber JI, Kim KH, Natterson PD, Lawrence T, Yang P, Weiss JN (1996) Effects of TNF-alpha on [Ca2+]i and contractility in isolated adult rabbit ventricular myocytes. Am J Phys Heart Circ Phys 271: H1449-H1455. https://doi.org/10.1152/ajpheart.1996.271.4.H1449

Gori T, Münzel T (2011) Oxidative stress and endothelial dysfunction: therapeutic implications. Ann Med 43:259-272. https://doi.org/10. 3109/07853890.2010.543920

Gregor MF, Hotamisligil GS (2011) Inflammatory mechanisms in obesity. Annu Rev Immunol 29:415-445. https://doi.org/10.1146/ annurev-immunol-031210-101322

Grützner A, Garcia-Manyes S, Kötter S, Badilla CL, Fernandez JM, Linke WA (2009) Modulation of titin-based stiffness by disulfide bonding in the cardiac titin N2-B unique sequence. Biophys J 97: 825-834. https://doi.org/10.1016/j.bpj.2009.05.037

Gulick T, Chung MK, Pieper SJ, Lange LG, Schreiner GF (1989) Interleukin 1 and tumor necrosis factor inhibit cardiac myocyte beta-adrenergic responsiveness. Proc Natl Acad Sci U S A 86: 6753-6757. https://doi.org/10.1073/pnas.86.17.6753

Hamdani N, Kooij V, van Dijk S et al (2008) Sarcomeric dysfunction in heart failure. Cardiovasc Res 77:649-658. https://doi.org/10.1093/ $\mathrm{cvr} / \mathrm{cvm} 079$

Hamdani N, Paulus WJ, van Heerebeek L et al (2009) Distinct myocardial effects of beta-blocker therapy in heart failure with normal and reduced left ventricular ejection fraction. Eur Heart J 30:1863-1872. https://doi.org/10.1093/eurheartj/ehp189

Hamdani N, Bishu KG, von Frieling-Salewsky M, Redfield MM, Linke WA (2013a) Deranged myofilament phosphorylation and function in experimental heart failure with preserved ejection fraction. Cardiovasc Res 97:464-471. https://doi.org/10.1093/cvr/cvs353

Hamdani N, Franssen C, Lourenco A et al (2013b) Myocardial titin hypophosphorylation importantly contributes to heart failure with preserved ejection fraction in a rat metabolic risk model. Circ Heart Fail 6:1239-1249. https://doi.org/10.1161/circheartfailure. 113.000539

Hamdani N, Krysiak J, Kreusser MM et al (2013c) Crucial role for Ca2(+ )/calmodulin-dependent protein kinase-II in regulating diastolic stress of normal and failing hearts via titin phosphorylation. Circ Res 112:664-674. https://doi.org/10.1161/circresaha.111.300105

Hamdani N, Hervent AS, Vandekerckhove L et al (2014) Left ventricular diastolic dysfunction and myocardial stiffness in diabetic mice is attenuated by inhibition of dipeptidyl peptidase 4. Cardiovasc Res 104:423-431. https://doi.org/10.1093/cvr/cvu223

Hamdani N, Herwig M, Linke WA (2017) Tampering with springs: phosphorylation of titin affecting the mechanical function of cardiomyocytes. Biophys Rev 9:225-237. https://doi.org/10.1007/ s12551-017-0263-9

Hara MR, Agrawal N, Kim SF et al (2005) S-nitrosylated GAPDH initiates apoptotic cell death by nuclear translocation following Siah1 binding. Nat Cell Biol 7:665-674. https://doi.org/10.1038/ncb1268

Hara MR, Cascio MB, Sawa A (2006) GAPDH as a sensor of NO stress. Biochim Biophys Acta 1762:502-509. https://doi.org/10.1016/j. bbadis.2006.01.012

Haworth RS, Stathopoulou K, Candasamy AJ, Avkiran M (2012) Neurohormonal regulation of cardiac histone deacetylase 5 nuclear localization by phosphorylation-dependent and phosphorylationindependent mechanisms. Circ Res 110:1585-1595. https://doi. org/10.1161/circresaha.111.263665

Haycock JW, MacNeil S, Jones P, Harris JB, Mantle D (1996) Oxidative damage to muscle protein in Duchenne muscular dystrophy. Neuroreport 8:357-361. https://doi.org/10.1097/00001756199612200-00070

He BJ, Joiner ML, Singh MV et al (2011) Oxidation of CaMKII determines the cardiotoxic effects of aldosterone. Nat Med 17:1610 1618. https://doi.org/10.1038/nm.2506

Heitzer T, Schlinzig T, Krohn K, Meinertz T, Münzel T (2001) Endothelial dysfunction, oxidative stress, and risk of cardiovascular events in patients with coronary artery disease. Circulation 104: 2673-2678. https://doi.org/10.1161/hc4601.099485

Herwig M, Kolijn D, Lódi M et al (2020) Modulation of titin-based stiffness in hypertrophic cardiomyopathy via protein kinase D. Front Physiol 11:240. https://doi.org/10.3389/fphys.2020.00240

Heymans S, Corsten MF, Verhesen W et al (2013) Macrophage microRNA-155 promotes cardiac hypertrophy and failure. Circulation 128:1420-1432. https://doi.org/10.1161/circulationaha. 112.001357

Ho FM, Liu SH, Liau CS, Huang PJ, Lin-Shiau SY (2000) High glucoseinduced apoptosis in human endothelial cells is mediated by sequential activations of c-Jun $\mathrm{NH}(2)$-terminal kinase and caspase-3. Circulation 101:2618-2624. https://doi.org/10.1161/01.cir.101.22. 2618

Holmström KM, Finkel T (2014) Cellular mechanisms and physiological consequences of redox-dependent signalling. Nat Rev Mol Cell Biol 15:411-421. https://doi.org/10.1038/nrm3801

Honold L, Nahrendorf M (2018) Resident and monocyte-derived macrophages in cardiovascular disease. Circ Res 122:113-127. https://doi. org/10.1161/circresaha.117.311071

Hudmon A, Schulman H (2002) Structure-function of the multifunctional $\mathrm{Ca} 2+/$ calmodulin-dependent protein kinase II. Biochem J 364:593611. https://doi.org/10.1042/bj20020228

Hulsmans M, Sager HB, Roh JD et al (2018) Cardiac macrophages promote diastolic dysfunction. J Exp Med 215:423-440. https://doi.org/ 10.1084/jem.20171274

Ito K, Lim S, Caramori G, Chung KF, Barnes PJ, Adcock IM (2001) Cigarette smoking reduces histone deacetylase 2 expression, enhances cytokine expression, and inhibits glucocorticoid actions in alveolar macrophages. FASEB J 15:1110-1112

Ito K, Hanazawa T, Tomita K, Barnes PJ, Adcock IM (2004) Oxidative stress reduces histone deacetylase 2 activity and enhances IL- 8 gene expression: role of tyrosine nitration. Biochem Biophys Res Commun 315:240-245. https://doi.org/10.1016/j.bbrc.2004.01.046

Janabi M, Yamashita S, Hirano K et al (2000) Oxidized LDL-induced NF-kappa B activation and subsequent expression of proinflammatory genes are defective in monocyte-derived macrophages from CD36-deficient patients. Arterioscler Thromb Vasc Biol 20:19531960. https://doi.org/10.1161/01.atv.20.8.1953 
Jeong J, Jung Y, Na S et al (2011) Novel oxidative modifications in redox-active cysteine residues. Mol Cell Proteomics 10: M110.000513. https://doi.org/10.1074/mcp.M110.000513

Ji LL (2007) Antioxidant signaling in skeletal muscle: a brief review. Exp Gerontol 42:582-593. https://doi.org/10.1016/j.exger.2007.03.002

Kain D, Amit U, Yagil C et al (2016) Macrophages dictate the progression and manifestation of hypertensive heart disease. Int J Cardiol 203:381-395. https://doi.org/10.1016/j.ijcard.2015.10.126

Kalogeropoulos A, Georgiopoulou V, Psaty BM et al (2010) Inflammatory markers and incident heart failure risk in older adults: the Health ABC (Health, Aging, and Body Composition) study. J Am Coll Cardiol 55:2129-2137. https://doi.org/10.1016/j.jacc. 2009.12.045

Keith ME, Jeejeebhoy KN, Langer A, Kurian R, Barr A, O'Kelly B, Sole MJ (2001) A controlled clinical trial of vitamin E supplementation in patients with congestive heart failure. Am J Clin Nutr 73:219-224. https://doi.org/10.1093/ajen/73.2.219

Kentish JC, McCloskey DT, Layland J, Palmer S, Leiden JM, Martin AF, Solaro RJ (2001) Phosphorylation of troponin I by protein kinase A accelerates relaxation and crossbridge cycle kinetics in mouse ventricular muscle. Circ Res 88:1059-1065. https://doi.org/10.1161/ hh1001.091640

Klaiber M, Dankworth B, Kruse M et al (2011) A cardiac pathway of cyclic GMP-independent signaling of guanylyl cyclase A, the receptor for atrial natriuretic peptide. Proc Natl Acad Sci U S A 108: 18500-18505. https://doi.org/10.1073/pnas.1103300108

Koitabashi N, Danner T, Zaiman AL et al (2011) Pivotal role of cardiomyocyte TGF- $\beta$ signaling in the murine pathological response to sustained pressure overload. J Clin Invest 121:2301-2312. https:// doi.org/10.1172/jci44824

Kolijn D, Kovács Á, Herwig M et al (2020a) Enhanced cardiomyocyte function in hypertensive rats with diastolic dysfunction and human heart failure patients after acute treatment with soluble guanylyl cyclase (sGC) activator:11. https://doi.org/10.3389/fphys.2020. 00345

Kolijn D, Pabel S, Tian Y et al (2020b) Empagliflozin improves endothelial and cardiomyocyte function in human heart failure with preserved ejection fraction via reduced pro-inflammatory-oxidative pathways and protein kinase $\mathrm{G} \alpha$ oxidation. Cardiovasc Res. https://doi.org/10.1093/cvr/cvaa123

Kosuri P, Alegre-Cebollada J, Feng J et al (2012) Protein folding drives disulfide formation. Cell 151:794-806. https://doi.org/10.1016/j. cell.2012.09.036

Kötter S, Unger A, Hamdani N, Lang P, Vorgerd M, Nagel-Steger L, Linke WA (2014) Human myocytes are protected from titin aggregation-induced stiffening by small heat shock proteins. J Cell Biol 204:187-202. https://doi.org/10.1083/jcb.201306077

Kratz M, Coats BR, Hisert KB et al (2014) Metabolic dysfunction drives a mechanistically distinct proinflammatory phenotype in adipose tissue macrophages. Cell Metab 20:614-625. https://doi.org/10. 1016/j.cmet.2014.08.010

Krown KA, Page MT, Nguyen C et al (1996) Tumor necrosis factor alpha-induced apoptosis in cardiac myocytes. Involvement of the sphingolipid signaling cascade in cardiac cell death. J Clin Invest 98:2854-2865. https://doi.org/10.1172/jci119114

Kubota T, McTiernan CF, Frye CS et al (1997) Dilated cardiomyopathy in transgenic mice with cardiac-specific overexpression of tumor necrosis factor-alpha. Circ Res 81:627-635. https://doi.org/10. 1161/01.res.81.4.627

Kuhn M (2004) Molecular physiology of natriuretic peptide signalling. Basic Res Cardiol 99:76-82. https://doi.org/10.1007/s00395-0040460-0

Kuster GM, Siwik DA, Pimentel DR, Colucci WS (2006) Role of reversible, thioredoxin-sensitive oxidative protein modifications in cardiac myocytes. Antioxid Redox Signal 8:2153-2159. https://doi.org/10. 1089/ars.2006.8.2153
Kwon SH, Pimentel DR, Remondino A, Sawyer DB, Colucci WS (2003) $\mathrm{H}(2) \mathrm{O}(2)$ regulates cardiac myocyte phenotype via concentrationdependent activation of distinct kinase pathways. J Mol Cell Cardiol 35:615-621. https://doi.org/10.1016/s0022-2828(03)00084-1

Lancel S, Zhang J, Evangelista A et al (2009) Nitroxyl activates SERCA in cardiac myocytes via glutathiolation of cysteine 674 . Circ Res 104:720-723. https://doi.org/10.1161/circresaha.108.188441

Lee DI, Zhu G, Sasaki T et al (2015) Phosphodiesterase 9A controls nitric-oxide-independent cGMP and hypertrophic heart disease. Nature 519:472-476. https://doi.org/10.1038/nature14332

Lee TM, Chang NC, Lin SZ (2017) Dapagliflozin, a selective SGLT2 inhibitor, attenuated cardiac fibrosis by regulating the macrophage polarization via STAT3 signaling in infarcted rat hearts. Free Radic Biol Med 104:298-310. https://doi.org/10.1016/j.freeradbiomed. 2017.01.035

Lehnart SE, Wehrens XH, Kushnir A, Marks AR (2004) Cardiac ryanodine receptor function and regulation in heart disease. Ann N Y Acad Sci 1015:144-159. https://doi.org/10.1196/annals.1302.012

Li N, Karin M (1999) Is NF-kappaB the sensor of oxidative stress? FASEB J 13:1137-1143

Li YY, Feng YQ, Kadokami T, McTiernan CF, Draviam R, Watkins SC, Feldman AM (2000) Myocardial extracellular matrix remodeling in transgenic mice overexpressing tumor necrosis factor alpha can be modulated by anti-tumor necrosis factor alpha therapy. Proc Natl Acad Sci U S A 97:12746-12751. https://doi.org/10.1073/pnas.97. 23.12746

Li X, Fang P, Mai J, Choi ET, Wang H, Yang XF (2013) Targeting mitochondrial reactive oxygen species as novel therapy for inflammatory diseases and cancers. J Hematol Oncol 6:19. https://doi.org/ 10.1186/1756-8722-6-19

Li X, Fang P, Li Y et al (2016) Mitochondrial reactive oxygen species mediate lysophosphatidylcholine-induced endothelial cell activation. Arterioscler Thromb Vasc Biol 36:1090-1100. https://doi. org/10.1161/atvbaha.115.306964

Li X, Fang P, Yang WY et al (2017) Mitochondrial ROS, uncoupled from ATP synthesis, determine endothelial activation for both physiological recruitment of patrolling cells and pathological recruitment of inflammatory cells. Can J Physiol Pharmacol 95:247-252. https:// doi.org/10.1139/cjpp-2016-0515

Ling H, Zhang T, Pereira L et al (2009) Requirement for Ca2+/calmodulin-dependent kinase II in the transition from pressure overloadinduced cardiac hypertrophy to heart failure in mice. J Clin Invest 119:1230-1240. https://doi.org/10.1172/jci38022

Linke WA, Hamdani N (2014) Gigantic business: titin properties and function through thick and thin. Circ Res 114:1052-1068. https:// doi.org/10.1161/circresaha.114.301286

Little C, O'Brien PJ (1969) Mechanism of peroxide-inactivation of the sulphydryl enzyme glyceraldehyde-3-phosphate dehydrogenase. Eur J Biochem 10:533-538. https://doi.org/10.1111/j.1432-1033. 1969.tb00721.x

Litwin SE, Bridge JH (1997) Enhanced $\mathrm{Na}(+)-\mathrm{Ca} 2+$ exchange in the infarcted heart. Implications for excitation-contraction coupling. Circ Res 81:1083-1093. https://doi.org/10.1161/01.res.81.6.1083

Luo M, Guan X, Luczak ED et al (2013) Diabetes increases mortality after myocardial infarction by oxidizing CaMKII. J Clin Invest 123: 1262-1274. https://doi.org/10.1172/jci65268

Maack C, Kartes T, Kilter H, Schäfers H-J, Nickenig G, Böhm M, Laufs U (2003) Oxygen free radical release in human failing myocardium is associated with increased activity of Rac1-GTPase and represents a target for statin treatment. Circulation 108:1567-1574. https://doi. org/10.1161/01.CIR.0000091084.46500.BB

Maier LS, Bers DM (2007) Role of Ca2+/calmodulin-dependent protein kinase $(\mathrm{CaMK})$ in excitation-contraction coupling in the heart. Cardiovasc Res 73:631-640. https://doi.org/10.1016/j.cardiores. 2006.11.005 
Maier LS, Zhang T, Chen L, DeSantiago J, Brown JH, Bers DM (2003) Transgenic CaMKIIdeltaC overexpression uniquely alters cardiac myocyte $\mathrm{Ca} 2+$ handling: reduced $\mathrm{SR} \mathrm{Ca} 2+$ load and activated SR Ca2+ release. Circ Res 92:904-911. https://doi.org/10.1161/01.res. 0000069685.20258.f1

Mann DL (2002) Inflammatory mediators and the failing heart: past, present, and the foreseeable future. Circ Res 91:988-998. https:// doi.org/10.1161/01.res.0000043825.01705.1b

Martinez FO, Sica A, Mantovani A, Locati M (2008) Macrophage activation and polarization. Front Biosci 13:453-461. https://doi.org/10. $2741 / 2692$

Marx N, McGuire DK (2016) Sodium-glucose cotransporter-2 inhibition for the reduction of cardiovascular events in high-risk patients with diabetes mellitus. Eur Heart J 37:3192-3200. https://doi.org/10. 1093/eurheartj/ehw110

Matough FA, Budin SB, Hamid ZA, Alwahaibi N, Mohamed J (2012) The role of oxidative stress and antioxidants in diabetic complications. Sultan Qaboos Univ Med J 12:5-18. https://doi.org/10.12816/ 0003082

Mehta JL, Pothineni NV (2016) Inflammation in heart failure: the holy grail? Hypertension 68:27-29. https://doi.org/10.1161/ hypertensionaha.116.07307

Meijer RI, Serne EH, Smulders YM, van Hinsbergh VW, Yudkin JS, Eringa EC (2011) Perivascular adipose tissue and its role in type 2 diabetes and cardiovascular disease. Curr Diab Rep 11:211-217. https://doi.org/10.1007/s11892-011-0186-y

Meldrum DR (1998) Tumor necrosis factor in the heart. Am J Phys 274: R577-R595. https://doi.org/10.1152/ajpregu.1998.274.3.R577

Mohamed AK, Bierhaus A, Schiekofer S, Tritschler H, Ziegler R, Nawroth PP (1999) The role of oxidative stress and NF-kappaB activation in late diabetic complications. Biofactors 10:157-167. https://doi.org/10.1002/biof.5520100211

Mohr S, Stamler JS, Brüne B (1996) Posttranslational modification of glyceraldehyde-3-phosphate dehydrogenase by S-nitrosylation and subsequent NADH attachment. J Biol Chem 271:4209-4214. https://doi.org/10.1074/jbc.271.8.4209

Mohr S, Hallak H, de Boitte A, Lapetina EG, Brüne B (1999) Nitric oxide-induced S-glutathionylation and inactivation of glyceraldehyde-3-phosphate dehydrogenase. J Biol Chem 274: 9427-9430. https://doi.org/10.1074/jbc.274.14.9427

Mollnau H, Oelze M, August M et al (2005) Mechanisms of increased vascular superoxide production in an experimental model of idiopathic dilated cardiomyopathy. Arterioscler Thromb Vasc Biol 25: 2554-2559. https://doi.org/10.1161/01.atv.0000190673.41925.9b

Moltzau LR, Aronsen JM, Meier S et al (2014a) Different compartmentation of responses to brain natriuretic peptide and C-type natriuretic peptide in failing rat ventricle. J Pharmacol Exp Ther 350:681-690. https://doi.org/10.1124/jpet.114.214882

Moltzau LR, Meier S, Aronsen JM et al (2014b) Differential regulation of C-type natriuretic peptide-induced cGMP and functional responses by PDE2 and PDE3 in failing myocardium. Naunyn Schmiedeberg's Arch Pharmacol 387:407-417. https://doi.org/10.1007/s00210-0130953-1

Morrow JD (2003) Is oxidant stress a connection between obesity and atherosclerosis? Arterioscler Thromb Vasc Biol 23:368-370. https:// doi.org/10.1161/01.atv.0000063107.86298.fd

Murray PJ, Wynn TA (2011) Protective and pathogenic functions of macrophage subsets. Nat Rev Immunol 11:723-737. https://doi. org/10.1038/nri3073

Murray PJ, Allen JE, Biswas SK et al (2014) Macrophage activation and polarization: nomenclature and experimental guidelines. Immunity 41:14-20. https://doi.org/10.1016/j.immuni.2014.06.008

Myung SK, Ju W, Cho B, Oh SW, Park SM, Koo BK, Park BJ (2013) Efficacy of vitamin and antioxidant supplements in prevention of cardiovascular disease: systematic review and meta-analysis of randomised controlled trials. Bmj 346:f10. https://doi.org/10.1136/ bmj.f10

Nakamura K, Fushimi K, Kouchi H, Mihara K, Miyazaki M, Ohe T, Namba M (1998) Inhibitory effects of antioxidants on neonatal rat cardiac myocyte hypertrophy induced by tumor necrosis factoralpha and angiotensin II. Circulation 98:794-799. https://doi.org/ 10.1161/01.cir.98.8.794

Nakamura T, Ranek MJ, Lee DI, Shalkey Hahn V, Kim C, Eaton P, Kass DA (2015) Prevention of PKG $1 \alpha$ oxidation augments cardioprotection in the stressed heart. J Clin Invest 125:24682472. https://doi.org/10.1172/jci80275

Navarro-Yepes J, Zavala-Flores L, Anandhan A et al (2014) Antioxidant gene therapy against neuronal cell death. Pharmacol Ther 142:206 230. https://doi.org/10.1016/j.pharmthera.2013.12.007

Neal B, Perkovic V, Mahaffey KW et al (2017) Canagliflozin and cardiovascular and renal events in type 2 diabetes. N Engl J Med 377: 644-657. https://doi.org/10.1056/NEJMoa1611925

Nicholls C, Li H, Liu JP (2012) GAPDH: a common enzyme with uncommon functions. Clin Exp Pharmacol Physiol 39:674-679. https://doi.org/10.1111/j.1440-1681.2011.05599.x

Obata T, Brown GE, Yaffe MB (2000) MAP kinase pathways activated by stress: the p38 MAPK pathway. Critical care medicine 28

Pabel S, Wagner S, Bollenberg $\mathrm{H}$ et al (2018) Empagliflozin directly improves diastolic function in human heart failure. Eur J Heart Fail 20:1690-1700. https://doi.org/10.1002/ejhf.1328

Pabel S, Mustroph J, Stehle T et al (2020) Dantrolene reduces CaMKII $\delta$ C-mediated atrial arrhythmias. Europace. https://doi.org/ 10.1093/europace/euaa079

Paulus WJ, Tschöpe C (2013) A novel paradigm for heart failure with preserved ejection fraction: comorbidities drive myocardial dysfunction and remodeling through coronary microvascular endothelial inflammation. J Am Coll Cardiol 62:263-271. https://doi.org/10. 1016/j.jacc.2013.02.092

Pazin MJ, Kadonaga JT (1997) What's up and down with histone deacetylation and transcription? Cell 89:325-328. https://doi.org/ 10.1016/s0092-8674(00)80211-1

Pitocco D, Zaccardi F, Di Stasio E, Romitelli F, Santini SA, Zuppi C, Ghirlanda G (2010) Oxidative stress, nitric oxide, and diabetes. Rev Diabet Stud 7:15-25. https://doi.org/10.1900/rds.2010.7.15

Ponikowski P, Voors AA, Anker SD et al (2016a) 2016 ESC guidelines for the diagnosis and treatment of acute and chronic heart failure: The Task Force for the diagnosis and treatment of acute and chronic heart failure of the European Society of Cardiology (ESC). Developed with the special contribution of the Heart Failure Association (HFA) of the ESC. Eur J Heart Fail 18:891-975. https://doi.org/10.1002/ejhf.592

Ponikowski P, Voors AA, Anker SD et al (2016b) 2016 ESC guidelines for the diagnosis and treatment of acute and chronic heart failure: The Task Force for the diagnosis and treatment of acute and chronic heart failure of the European Society of Cardiology (ESC) developed with the special contribution of the Heart Failure Association (HFA) of the ESC. Eur Heart J 37:2129-2200. https://doi.org/10. 1093/eurheartj/ehw128

Posterino GS, Lamb GD (1996) Effects of reducing agents and oxidants on excitation-contraction coupling in skeletal muscle fibres of rat and toad. J Physiol 496(Pt 3):809-825. https://doi.org/10.1113/ jphysiol.1996.sp021729

Prysyazhna O, Rudyk O, Eaton P (2012) Single atom substitution in mouse protein kinase $\mathrm{G}$ eliminates oxidant sensing to cause hypertension. Nat Med 18:286-290. https://doi.org/10.1038/nm.2603

Prysyazhna O, Burgoyne JR, Scotcher J, Grover S, Kass D, Eaton P (2016) Phosphodiesterase 5 inhibition limits doxorubicin-induced heart failure by attenuating protein kinase $\mathrm{G} \mathrm{I} \alpha$ oxidation. J Biol Chem 291:17427-17436. https://doi.org/10.1074/jbc.M1 16.724070

Pulkki KJ (1997) Cytokines and cardiomyocyte death. Ann Med 29:339 343. https://doi.org/10.3109/07853899708999358 
Purohit A, Rokita AG, Guan X et al (2013) Oxidized Ca(2+)/calmodulindependent protein kinase II triggers atrial fibrillation. Circulation 128:1748-1757. https://doi.org/10.1161/circulationaha.113.003313

Reichart G, Mayer J, Zehm C et al (2019) Mitochondrial complex IV mutation increases reactive oxygen species production and reduces lifespan in aged mice. Acta Physiol (Oxford) 225:e13214. https:// doi.org/10.1111/apha.13214

Riehle C, Abel ED (2016) Insulin signaling and heart failure. Circ Res 118:1151-1169. https://doi.org/10.1161/circresaha.116.306206

Riehle C, Bauersachs J (2018) Of mice and men: models and mechanisms of diabetic cardiomyopathy. Basic Res Cardiol 114:2. https://doi. org/10.1007/s00395-018-0711-0

Rodríguez-Pascual F, Redondo-Horcajo M, Magán-Marchal N, Lagares D, Martínez-Ruiz A, Kleinert H, Lamas S (2008) Glyceraldehyde-3phosphate dehydrogenase regulates endothelin-1 expression by a novel, redox-sensitive mechanism involving mRNA stability. Mol Cell Biol 28:7139-7155. https://doi.org/10.1128/mcb.01145-08

Salas MA, Valverde CA, Sánchez G et al (2010) The signalling pathway of CaMKII-mediated apoptosis and necrosis in the ischemia/ reperfusion injury. J Mol Cell Cardiol 48:1298-1306. https://doi. org/10.1016/j.yjmcc.2009.12.015

Sandner P, Zimmer DP, Milne GT, Follmann M, Hobbs A, Stasch JP (2019) Soluble guanylate cyclase stimulators and activators. Handb Exp Pharmacol. https://doi.org/10.1007/164_2018_197

Sato H, Shibata M, Shimizu T et al (2013) Differential cellular localization of antioxidant enzymes in the trigeminal ganglion. Neuroscience 248:345-358. https://doi.org/10.1016/j.neuroscience. 2013.06.010

Schmidt-Lucke C, Escher F, Van Linthout S et al (2015) Cardiac migration of endogenous mesenchymal stromal cells in patients with inflammatory cardiomyopathy. Mediat Inflamm 2015:308185. https:// doi.org/10.1155/2015/308185

Sen N, Hara MR, Kornberg MD et al (2008) Nitric oxide-induced nuclear GAPDH activates p300/CBP and mediates apoptosis. Nat Cell Biol 10:866-873. https://doi.org/10.1038/ncb1747

Sena CM, Pereira AM, Seiça R (2013) Endothelial dysfunction - a major mediator of diabetic vascular disease. Biochim Biophys Acta 1832: 2216-2231. https://doi.org/10.1016/j.bbadis.2013.08.006

Sharma R, Coats AJ, Anker SD (2000) The role of inflammatory mediators in chronic heart failure: cytokines, nitric oxide, and endothelin1. Int J Cardiol 72:175-186. https://doi.org/10.1016/s01675273(99)00186-2

Singal PK, Khaper N, Palace V, Kumar D (1998) The role of oxidative stress in the genesis of heart disease. Cardiovasc Res 40:426-432. https://doi.org/10.1016/s0008-6363(98)00244-2

Singh MV, Kapoun A, Higgins L et al (2009) Ca2+/calmodulin-dependent kinase II triggers cell membrane injury by inducing complement factor B gene expression in the mouse heart. J Clin Invest 119: 986-996. https://doi.org/10.1172/jci35814

Sivasubramanian N, Coker ML, Kurrelmeyer KM, MacLellan WR, DeMayo FJ, Spinale FG, Mann DL (2001) Left ventricular remodeling in transgenic mice with cardiac restricted overexpression of tumor necrosis factor. Circulation 104:826-831. https://doi.org/10. 1161/hc3401.093154

Siwik DA, Tzortzis JD, Pimental DR et al (1999) Inhibition of copperzinc superoxide dismutase induces cell growth, hypertrophic phenotype, and apoptosis in neonatal rat cardiac myocytes in vitro. Circ Res 85:147-153. https://doi.org/10.1161/01.res.85.2.147

Siwik DA, Pagano PJ, Colucci WS (2001) Oxidative stress regulates collagen synthesis and matrix metalloproteinase activity in cardiac fibroblasts. Am J Phys Cell Physiol 280:C53-C60. https://doi.org/ 10.1152/ajpcell.2001.280.1.C53

Solaro RJ (2008) Multiplex kinase signaling modifies cardiac function at the level of sarcomeric proteins. J Biol Chem 283:26829-26833. https://doi.org/10.1074/jbc.R800037200
Solaro RJ, de Tombe PP (2008) Review focus series: sarcomeric proteins as key elements in integrated control of cardiac function. Cardiovasc Res 77:616-618. https://doi.org/10.1093/cvr/cvn004

Solomon SD, McMurray JJV, Anand IS et al (2019) Angiotensinneprilysin inhibition in heart failure with preserved ejection fraction. N Engl J Med 381:1609-1620. https://doi.org/10.1056/ NEJMoa1908655

Solsona C, Kahn TB, Badilla CL, Álvarez-Zaldiernas C, Blasi J, Fernandez JM, Alegre-Cebollada J (2014) Altered thiol chemistry in human amyotrophic lateral sclerosis-linked mutants of superoxide dismutase 1. J Biol Chem 289:26722-26732. https://doi.org/10. 1074/jbc.M114.565333

Sorop O, Heinonen I, van Kranenburg M et al (2018) Multiple common comorbidities produce left ventricular diastolic dysfunction associated with coronary microvascular dysfunction, oxidative stress, and myocardial stiffening. Cardiovasc Res 114:954-964. https://doi.org/ $10.1093 / \mathrm{cvr} / \mathrm{cvy} 038$

Souza JM, Radi R (1998) Glyceraldehyde-3-phosphate dehydrogenase inactivation by peroxynitrite. Arch Biochem Biophys 360:187194. https://doi.org/10.1006/abbi.1998.0932

Spiecker M, Darius H, Kaboth K, Hübner F, Liao JK (1998) Differential regulation of endothelial cell adhesion molecule expression by nitric oxide donors and antioxidants. J Leukoc Biol 63:732-739

Srinivasan S, Hatley ME, Bolick DT, Palmer LA, Edelstein D, Brownlee M, Hedrick CC (2004) Hyperglycaemia-induced superoxide production decreases eNOS expression via AP-1 activation in aortic endothelial cells. Diabetologia 47:1727-1734. https://doi.org/10. 1007/s00125-004-1525-1

Stasch JP, Becker EM, Alonso-Alija C et al (2001) NO-independent regulatory site on soluble guanylate cyclase. Nature 410:212-215. https://doi.org/10.1038/35065611

Stasch JP, Pacher P, Evgenov OV (2011) Soluble guanylate cyclase as an emerging therapeutic target in cardiopulmonary disease. Circulation 123:2263-2273. https://doi.org/10.1161/circulationaha.110.981738

Sugden PH, Clerk A (1998a) Cellular mechanisms of cardiac hypertrophy. J Mol Med (Berl) 76:725-746. https://doi.org/10.1007/ s001090050275

Sugden PH, Clerk A (1998b) "stress-responsive" mitogen-activated protein kinases (c-Jun N-terminal kinases and p38 mitogen-activated protein kinases) in the myocardium. Circ Res 83:345-352. https:// doi.org/10.1161/01.res.83.4.345

Sumimoto H, Miyano K, Takeya R (2005) Molecular composition and regulation of the Nox family NAD $(\mathrm{P}) \mathrm{H}$ oxidases. Biochem Biophys Res Commun 338:677-686. https://doi.org/10.1016/j.bbrc.2005.08. 210

Swaminathan PD, Purohit A, Hund TJ, Anderson ME (2012) Calmodulin-dependent protein kinase II: linking heart failure and arrhythmias. Circ Res 110:1661-1677. https://doi.org/10.1161/ circresaha.111.243956

Swinnen M, Vanhoutte D, Van Almen GC et al (2009) Absence of thrombospondin-2 causes age-related dilated cardiomyopathy. Circulation 120:1585-1597. https://doi.org/10.1161/circulationaha. 109.863266

Tahara A, Kurosaki E, Yokono M et al (2013) Effects of SGLT2 selective inhibitor ipragliflozin on hyperglycemia, hyperlipidemia, hepatic steatosis, oxidative stress, inflammation, and obesity in type 2 diabetic mice. Eur J Pharmacol 715:246-255. https://doi.org/10.1016/j. ejphar.2013.05.014

Tahara A, Kurosaki E, Yokono M et al (2014) Effects of sodium-glucose cotransporter 2 selective inhibitor ipragliflozin on hyperglycaemia, oxidative stress, inflammation and liver injury in streptozotocininduced type 1 diabetic rats. J Pharm Pharmacol 66:975-987. https://doi.org/10.1111/jphp.12223

Tak PP, Firestein GS (2001) NF-kappaB: a key role in inflammatory diseases. J Clin Invest 107:7-11. https://doi.org/10.1172/jci11830 
Taniguchi CM, Emanuelli B, Kahn CR (2006) Critical nodes in signalling pathways: insights into insulin action. Nat Rev Mol Cell Biol 7:8596. https://doi.org/10.1038/nrm1837

Taniyama Y, Griendling KK (2003) Reactive oxygen species in the vasculature: molecular and cellular mechanisms. Hypertension 42: 1075-1081. https://doi.org/10.1161/01.hyp.0000100443.09293.4f

Testa M, Yeh M, Lee P, Fanelli R, Loperfido F, Berman JW, LeJemtel TH (1996) Circulating levels of cytokines and their endogenous modulators in patients with mild to severe congestive heart failure due to coronary artery disease or hypertension. J Am Coll Cardiol 28:964-971. https://doi.org/10.1016/s0735-1097(96)00268-9

Tian L, Fong MP, Wang JJ, Wei NE, Jiang H, Doerge RW, Chen ZJ (2005) Reversible histone acetylation and deacetylation mediate genome-wide, promoter-dependent and locus-specific changes in gene expression during plant development. Genetics 169:337-345. https://doi.org/10.1534/genetics.104.033142

Tibbles LA, Woodgett JR (1999) The stress-activated protein kinase pathways. Cell Mol Life Sci 55:1230-1254. https://doi.org/10. 1007/s000180050369

Tisdale EJ (2001) Glyceraldehyde-3-phosphate dehydrogenase is required for vesicular transport in the early secretory pathway. J Biol Chem 276:2480-2486. https://doi.org/10.1074/jbc.M007567200

Tisdale EJ (2002) Glyceraldehyde-3-phosphate dehydrogenase is phosphorylated by protein kinase Ciota /lambda and plays a role in microtubule dynamics in the early secretory pathway. J Biol Chem 277:3334-3341. https://doi.org/10.1074/jbc.M109744200

Toischer K, Rokita AG, Unsöld B et al (2010) Differential cardiac remodeling in preload versus afterload. Circulation 122:993-1003. https://doi.org/10.1161/circulationaha.110.943431

Torre-Amione G, Kapadia S, Lee J, Durand JB, Bies RD, Young JB, Mann DL (1996) Tumor necrosis factor-alpha and tumor necrosis factor receptors in the failing human heart. Circulation 93:704-711. https://doi.org/10.1161/01.cir.93.4.704

Trippel TD, Van Linthout S, Westermann D et al (2018) Investigating a biomarker-driven approach to target collagen turnover in diabetic heart failure with preserved ejection fraction patients. Effect of torasemide versus furosemide on serum $\mathrm{C}$-terminal propeptide of procollagen type I (DROP-PIP trial). Eur J Heart Fail 20:460-470. https://doi.org/10.1002/ejhf.960

Tromp J, Westenbrink BD, Ouwerkerk W et al (2018) Identifying pathophysiological mechanisms in heart failure with reduced versus preserved ejection fraction. J Am Coll Cardiol 72:1081-1090. https:// doi.org/10.1016/j.jacc.2018.06.050

Ullrich ND, Fanchaouy M, Gusev K, Shirokova N, Niggli E (2009) Hypersensitivity of excitation-contraction coupling in dystrophic cardiomyocytes. Am J Physiol Heart Circ Physiol 297:H1992H2003. https://doi.org/10.1152/ajpheart.00602.2009

Valgimigli M, Curello S, Ceconi C et al (2001) Neurohormones, cytokines and programmed cell death in heart failure: a new paradigm for the remodeling heart. Cardiovasc Drugs Ther 15:529-537. https://doi.org/10.1023/a:1013771805743

van Amerongen MJ, Harmsen MC, van Rooijen N, Petersen AH, van Luyn MJ (2007) Macrophage depletion impairs wound healing and increases left ventricular remodeling after myocardial injury in mice. Am J Pathol 170:818-829. https://doi.org/10.2353/ajpath.2007. 060547

van Heerebeek L, Borbély A, Niessen HW et al (2006) Myocardial structure and function differ in systolic and diastolic heart failure. Circulation 113:1966-1973. https://doi.org/10.1161/circulationaha. 105.587519

van Heerebeek L, Hamdani N, Handoko ML et al (2008) Diastolic stiffness of the failing diabetic heart: importance of fibrosis, advanced glycation end products, and myocyte resting tension. Circulation 117:43-51. https://doi.org/10.1161/circulationaha.107.728550

van Heerebeek L, Hamdani N, Falcão-Pires I et al (2012) Low myocardial protein kinase $\mathrm{G}$ activity in heart failure with preserved ejection fraction. Circulation 126:830-839. https://doi.org/10.1161/ circulationaha.111.076075

Vila-Petroff M, Salas MA, Said M et al (2007) CaMKII inhibition protects against necrosis and apoptosis in irreversible ischemiareperfusion injury. Cardiovasc Res 73:689-698. https://doi.org/10. 1016/j.cardiores.2006.12.003

Wagner S, Rokita AG, Anderson ME, Maier LS (2013) Redox regulation of sodium and calcium handling. Antioxid Redox Signal 18:10631077. https://doi.org/10.1089/ars.2012.4818

Wang Z, Nakayama T (2010) Inflammation, a link between obesity and cardiovascular disease. Mediat Inflamm 2010:535918. https://doi. org/10.1155/2010/535918

West AP, Brodsky IE, Rahner C et al (2011) TLR signalling augments macrophage bactericidal activity through mitochondrial ROS. Nature 472:476-480. https://doi.org/10.1038/nature09973

Wiviott SD, Raz I, Bonaca MP et al (2019) Dapagliflozin and cardiovascular outcomes in type 2 diabetes. N Engl J Med 380:347-357. https://doi.org/10.1056/NEJMoa1812389

Wu JQ, Kosten TR, Zhang XY (2013) Free radicals, antioxidant defense systems, and schizophrenia. Prog Neuro-Psychopharmacol Biol Psychiatry 46:200-206. https://doi.org/10.1016/j.pnpbp.2013.02. 015

Xiao L, Pimentel DR, Wang J, Singh K, Colucci WS, Sawyer DB (2002) Role of reactive oxygen species and $\mathrm{NAD}(\mathrm{P}) \mathrm{H}$ oxidase in alpha(1)adrenoceptor signaling in adult rat cardiac myocytes. Am J Phys Cell Physiol 282:C926-C934. https://doi.org/10.1152/ajpcell. 00254.2001

Xu L, Eu JP, Meissner G, Stamler JS (1998) Activation of the cardiac calcium release channel (ryanodine receptor) by poly-Snitrosylation. Science 279:234-237. https://doi.org/10.1126/ science.279.5348.234

Yokoyama T, Vaca L, Rossen RD, Durante W, Hazarika P, Mann DL (1993) Cellular basis for the negative inotropic effects of tumor necrosis factor-alpha in the adult mammalian heart. J Clin Invest 92:2303-2312. https://doi.org/10.1172/jci116834

Yokoyama T, Nakano M, Bednarczyk JL, McIntyre BW, Entman M, Mann DL (1997) Tumor necrosis factor-alpha provokes a hypertrophic growth response in adult cardiac myocytes. Circulation 95: 1247-1252. https://doi.org/10.1161/01.cir.95.5.1247

Zalk R, Lehnart SE, Marks AR (2007) Modulation of the ryanodine receptor and intracellular calcium. Annu Rev Biochem 76:367385. https://doi.org/10.1146/annurev.biochem.76.053105.094237

Zangar RC, Davydov DR, Verma S (2004) Mechanisms that regulate production of reactive oxygen species by cytochrome $\mathrm{P} 450$. Toxicol Appl Pharmacol 199:316-331. https://doi.org/10.1016/j. taap.2004.01.018

Zhang T, Maier LS, Dalton ND, Miyamoto S, Ross J Jr, Bers DM, Brown $\mathrm{JH}$ (2003) The deltaC isoform of CaMKII is activated in cardiac hypertrophy and induces dilated cardiomyopathy and heart failure. Circ Res 92:912-919. https://doi.org/10.1161/01.res.0000069686. 31472.c5

Zhang R, Khoo MS, Wu Y et al (2005) Calmodulin kinase II inhibition protects against structural heart disease. Nat Med 11:409-417. https://doi.org/10.1038/nm1215

Zheng L, Roeder RG, Luo Y (2003) S phase activation of the histone H2B promoter by OCA-S, a coactivator complex that contains GAPDH as a key component. Cell 114:255-266. https://doi.org/ 10.1016/s0092-8674(03)00552-x

Zinman B, Wanner C, Lachin JM et al (2015) Empagliflozin, cardiovascular outcomes, and mortality in type 2 diabetes. N Engl J Med 373: 2117-2128. https://doi.org/10.1056/NEJMoa1504720

Publisher's note Springer Nature remains neutral with regard to jurisdictional claims in published maps and institutional affiliations. 